\title{
Microstructure and Texture Evolution in a Post-dynamic Recrystallized Titanium During Annealing, Monotonic and Cyclic Loading
}

\author{
P.-C. ZHAO, B. CHEN, Z.-G. ZHENG, B. GUAN, X.-C. ZHANG, and S.-T. TU
}

The post-dynamic recrystallization behavior of ultrafine-grained (UFG: $0.44 \mu \mathrm{m}$ ) cp-Ti under annealing, room temperature (RT) monotonic and cyclic loading was investigated across a range of temperatures and deformation rates wherever appropriate. By characterizing the grain and boundary structures, it was confirmed that recrystallization and grain growth occurred due to annealing $\left(\geq 600{ }^{\circ} \mathrm{C}\right)$ and $R=-1$ fatigue at RT. There was a noticeable 30 deg aggregation in misorientation distribution, along with the increased grain size. However, the hypothetical correlation between $30 \mathrm{deg}$ aggregation and $\Sigma 13 \mathrm{a}$ or the other characteristic coincidence site lattice boundaries was found to be weak. The fatigue-induced grain growth is particularly intriguing for two reasons. First, the large monotonic deformation with low strain rate cannot trigger grain growth. Second, fatigue sharpened the basal intensity around the ND and caused a weaker texture component close to TD (load axis along the LD, perpendicular to the TD-ND plane). By contrast, high-temperature annealing only strengthened the UFG processing induced basal pole but without affecting its location. Novel insights into this fatigue-induced texture evolution in UFG cp-Ti has been provided. The lattice rotation during fatigue can be attributed to the combined effect of activation of prismatic $\langle a\rangle$ slip parallel to LD, and basal $\langle a\rangle$ slip perpendicular to it. The theoretically calculated stress to activate dislocation slip by assuming a non-equilibrium grain boundary state lent support to the above assertion. Moreover, the TEM observation evidently showed the characteristics of dislocation cross-slip and multiple slip in the grain interior.

P.-C. ZHAO, X.-C. ZHANG, and S.-T. TU are with the Key Laboratory of Pressure Systems and Safety, Ministry of Education, School of Mechanical and Power Engineering, East China University of Science and Technology, Shanghai 200237, P.R. China. Contact e-mail: xczhang@ecust.edu.cn B. CHEN is with the School of Engineering, University of Leicester, Leicester, LE1 7RH, UK. Contact e-mail: bo.chen@leicester.ac.uk Z.-G. ZHENG is with the College of Mechanical Engineering, Guangxi University, Nanning 530004, P.R. China. B. GUAN is with the National Engineering Research Center for Magnesium Alloys, Chongqing University, Chongqing 400044, P.R. China.

Manuscript submitted July 12, 2020; accepted October 15, 2020.

Article published online November 15, 2020 


\section{Graphical Abstract}

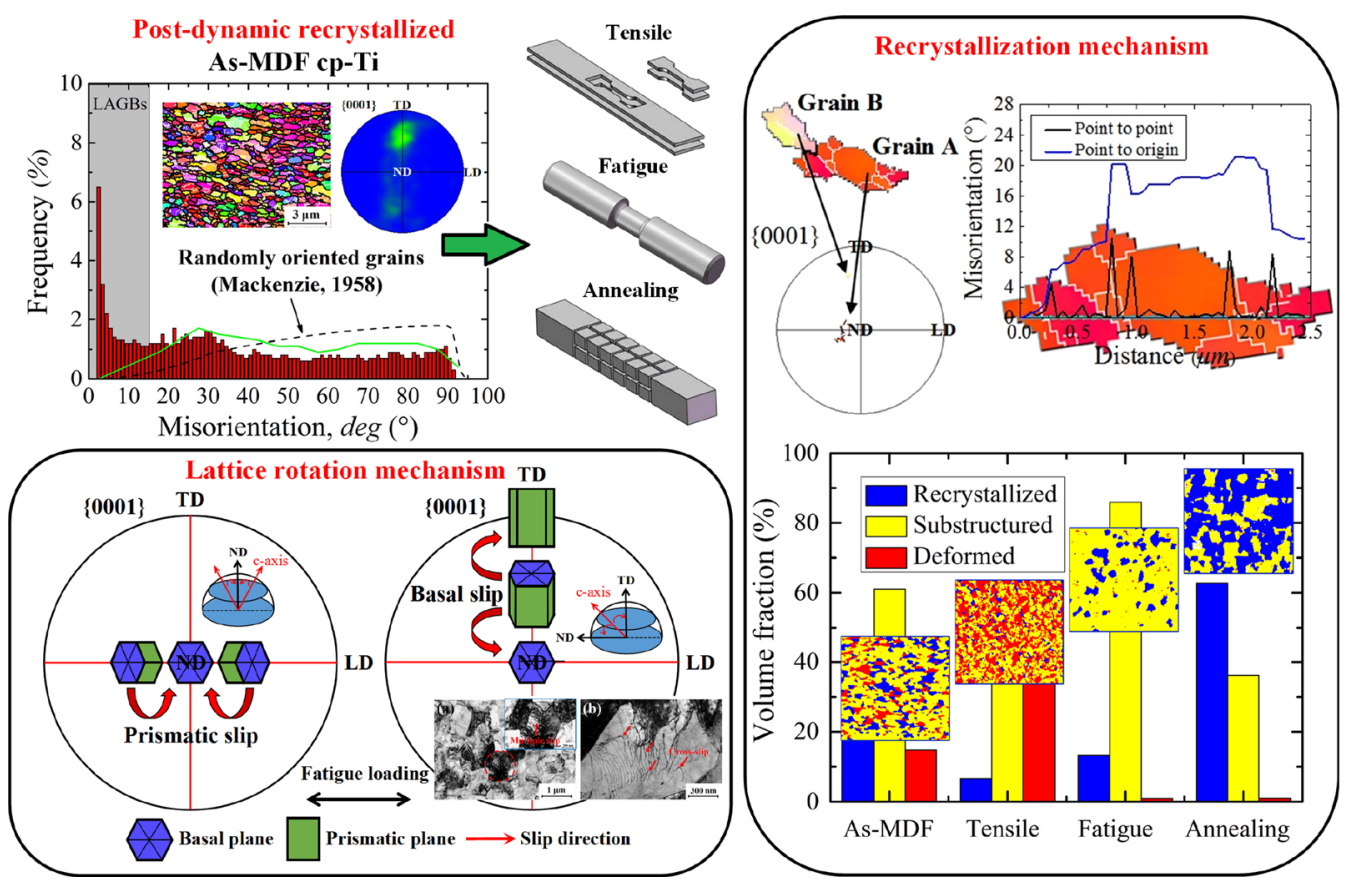

https://doi.org/10.1007/s11661-020-06071-x

(C) The Author(s) 2020

\section{INTRODUCTION}

THE generic term recrystallization describes the replacement of cold worked microstructure by forming new grains during annealing at temperatures of $\geq 0.5 T_{\mathrm{m}}$. This process is referred to as discontinuous static recrystallization. By contrast, discontinuous dynamic recrystallization (dDRX) occurs during high-temperature straining. For both cases, recrystallized grains co-exist with the deformed ones, hence a discontinuous process. The recrystallization mechanism was studied for several decades and a thorough review of the literature was published in 1997. ${ }^{[1]}$ Since then electron backscattered diffraction (EBSD) technique has become widespread and it enables mapping crystallographic orientations in a large number of grains with much reduced time compared to transmission electron microscopy (TEM). The paper published in $2014^{[2]}$ provided a comprehensive review on two types of dynamic recrystallization: $\mathrm{dDRX}$ and continuous dynamic recrystallization (cDRX). A later review paper ${ }^{[3]}$ considered the geometric DRX in addition to the above two. The evolving recrystallization terms can be attributed to the expansion of processing methods, in particular those arising from severe plastic deformation, SPD. ${ }^{[2]}$

The SPD-induced ultrafine grain (UFG) microstructure can be characterized by the gradual transformation of low-angle into high-angle grain boundaries (LAGBs to HAGBs), that is the essence of cDRX. The dynamic UFG formation is accompanied by a dramatic decrease in dislocation density at the grain interior, while the boundaries are in non-equilibrium state. ${ }^{[4]}$ Over the last decades, much improved knowledge has been gained about the creation of UFG microstructure and the underlying cDRX mechanism. ${ }^{[5]}$ However, the post-dynamic recrystallization behavior of UFG materials has not been explored very much. ${ }^{[2]}$

The annealing behavior was examined on a range of UFG materials that included $\mathrm{Cu}$, Type 304 stainless steel, $\mathrm{Ni}, \mathrm{Al}$ and $\mathrm{Mg} .{ }^{[2]}$ It can be concluded that continuous static recrystallization (cSRX) mechanism was responsible for the grain growth. Compared to the cubic materials, much fewer studies on hexagonal close packed (hcp) materials (hot-deformed AZ31 $\mathrm{Mg}^{[6,}{ }^{7]}$ ) have been published to date. Furthermore, limited work (both on $\mathrm{Mg}^{[8,9]}$ ) has been performed to elucidate the microstructure and texture evolution during fatigue loading. Therefore, further work is required in this field.

The present work focuses on commercially pure cp-Ti with the UFG microstructure created by multi-directional forging (MDF). The reason is twofold: first, basal $\langle a\rangle$ slip is no longer the only active slip system during deformation; and secondly, twinning activity is restricted due to the small size of grains and high stress threshold. Hence, this work is distinct from that in $\mathrm{Mg}$. Among the SPD methods, MDF is the simplest and can easily be scaled up for the processing of sizeable semi-products. ${ }^{[2]}$

Our previous work ${ }^{[10]}$ on MDF cp-Ti revealed that high-cycle fatigue loading at room temperature (RT) can promote the formation of a different but strong 
texture concurrently with the grain growth. However, we were unable to explain the reasons. A systematic study of MDF cp-Ti would be valuable, not only in elucidating the underlying mechanisms responsible for the dramatic texture change, but also in providing a complete picture of the post-dynamic recrystallization behavior under annealing, monotonic and cyclic loading. Using TEM, EBSD and transmission Kikuchi diffraction (TKD) techniques, deformation mechanisms of MDF cp-Ti were examined with particular focus on the orientation dependence of active slip modes of individual grains and their collective effect. The validity of the determined slip modes was also discussed based on the Schmid factor.

\section{EXPERIMENTAL}

\section{A. Material and Multi-directional Forging (MDF)}

Commercially pure titanium (cp-Ti, ASTM grade 2) with single $\alpha$-phase hcp crystal structure had a coarse grain size of $35 \pm 15 \mu \mathrm{m}$, measured using the linear intercept method. The chemical composition was $\mathrm{Fe}$ 0.28 pct, C 0.08 pct, N 0.03 pct, $\mathrm{H} 0.015$ pct, O 0.25 pet (all in wt pct) and Ti in balance. A set of cylindrical bar samples (35 $\mathrm{mm}$ in diameter and $60 \mathrm{~mm}$ in length) were pre-heated to $450{ }^{\circ} \mathrm{C}$, followed by high strain rate $(\sim 20$ $\left.\mathrm{s}^{-1}\right)$ forging. Three MDF cycles were performed to introduce a high cumulative strain of $\sim 5$. Within each MDF cycle, the hammer force was applied along three orthogonal directions. The strain applied to the normal (ND) and transversal (TD) planes was similar, hence no fundamental difference between the ND and TD. The final dimension of MDF billet was $23 \times 25 \times 90 \mathrm{~mm}^{3}$.

\section{B. Isothermal Annealing, Monotonic and Fatigue Loading}

The MDF cp-Ti was the starting material condition to study the post-dynamic recrystallization behavior during annealing, monotonic tensile and fatigue loading. Isothermal annealing was carried out in a muffle furnace and the temperature was controlled within $\pm 2{ }^{\circ} \mathrm{C}$. Cube specimens with $4 \times 5 \times 6 \mathrm{~mm}^{3}$ were cut from the middle part of the MDF billet, and the $5 \times 6 \mathrm{~mm}^{2}$ plane was parallel to the longitudinal direction (LD, Figure 1). The annealing temperature ranged from 400 to $800{ }^{\circ} \mathrm{C}$ and time from 1 to 4 hours, as summarized in Table I. Annealing temperatures were well below the $\beta$-transus of cp-Ti $\left(882^{\circ} \mathrm{C}\right)$.

In terms of the monotonic tensile loading, dog-bone shaped specimens with gauge cross-section of $0.5 \times 2.5$ $\mathrm{mm}^{2}$ and length of $8 \mathrm{~mm}$ were used (Figure 1). All specimens were made using wire-electrical discharge machining and tensile direction was parallel to the LD. Tensile tests were performed at RT on a Shimadzu servopulser micromechanical testing system, under constant displacement rates ranging from 0.05 to $5 \mathrm{~mm} /$ min. The corresponding strain rates were calculated as 1 $\times 10^{-4}, 5 \times 10^{-4}, 1 \times 10^{-3}, 5 \times 10^{-3}, 1 \times 10^{-2} \mathrm{~s}^{-1}$ (Table I).

In terms of the fatigue loading, two cylindrical specimens with gauge length of $14 \mathrm{~mm}$ and diameter of $8 \mathrm{~mm}$ were extracted from the MDF cp-Ti billet along the LD (Figure 1). Specimens were fatigued in air at RT, a constant stress amplitude of $280 \mathrm{MPa}, R=-1$ and frequency of $14 \mathrm{~Hz}$. One specimen was fatigued for 1000 cycles, while the other for $4.3 \times 10^{4}$ cycles with an equivalent loading time of $\sim 50$ minutes (Table I). The latter specimen is the same one as that studied by means

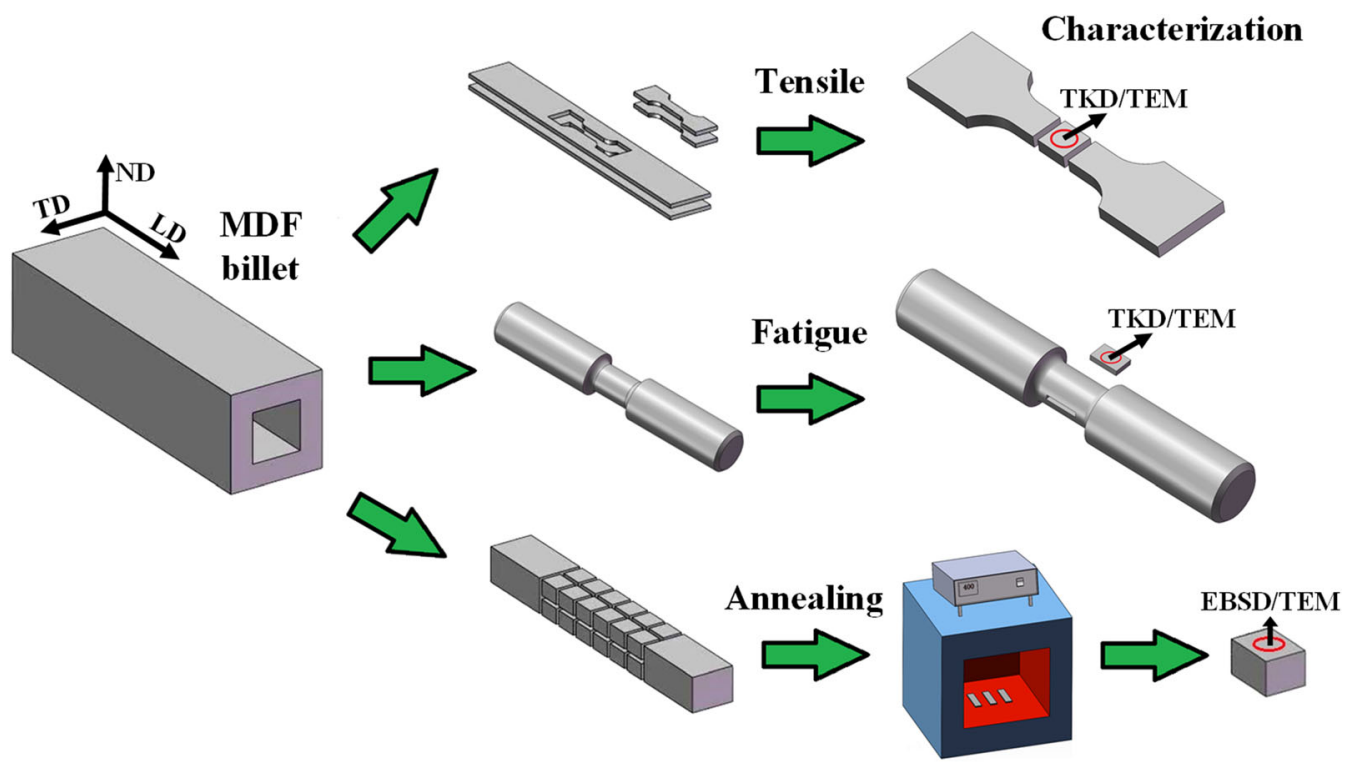

Fig. 1-A schematic showing the EBSD/TKD examination plane of annealed and loaded specimens with respect to the coordinate system defined for the MDF billet. ND, TD and LD denote normal, transversal and longitudinal directions, respectively. 
Table I. Summary of the As-MDF, Annealed and Loaded Specimens

\begin{tabular}{llcccc}
\hline $\begin{array}{l}\text { Sample } \\
\text { Condition }\end{array}$ & Temperature $\left({ }^{\circ} \mathrm{C}\right)$ & $\begin{array}{c}\text { Test Duration or Strain } \\
\text { Rate }\end{array}$ & $\begin{array}{c}\text { Grain Size } \\
(\mu \mathrm{m})\end{array}$ & $\begin{array}{c}\text { Hardness } \\
(\mathrm{HV})\end{array}$ & $\begin{array}{c}\text { Post-test } \\
\text { Examination }\end{array}$ \\
\hline As-MDF & $\mathrm{N} / \mathrm{A}$ & $\mathrm{N} / \mathrm{A}$ & 0.44 & $273.4 \pm 8.6$ & TKD \\
Annealing & 400,500 & $2,4 \mathrm{~h}$ & $\mathrm{~N} / \mathrm{A}$ & $268.8 \pm 9.0^{*}$ & TEM \\
& $600,700,800$ & $1,2,4 \mathrm{~h}$ & $1.83^{*}$ & $229.6 \pm 7.7^{*}$ & TEM, EBSD \\
Tensile & $\mathrm{RT}$ & $10^{-4}$ to $10^{-2} \mathrm{~s}^{-1}$ & $0.49^{*}$ & $272.5 \pm 10.4^{*}$ & TEM, TKD \\
Fatigue $R=-1$ & $\mathrm{RT}, 14 \mathrm{~Hz}, 280 \mathrm{MPa}$ & 1000 cycles & 0.80 & $244.2 \pm 7.4$ & $240.5 \pm 8.1$ \\
& & $4.3 \times 10^{4}$ cycles & 1.05 & 2.05 \\
\hline
\end{tabular}

*Data from the specimen annealed at $500^{\circ} \mathrm{C}$ for $4 \mathrm{~h}, 600^{\circ} \mathrm{C}$ for $1 \mathrm{~h}$ or loaded with a strain rate of $1 \times 10^{-4} \mathrm{~s}{ }^{-1}$.

of in situ neutron diffraction. ${ }^{[10]}$ All of the specimens that included both the tensile and fatigue were abraded using $\mathrm{SiC}$ paper up to 2000 grit and then polished by OPS to obtain a deformation-free surface condition. The typical surface roughness was measured to be $0.3 \mu \mathrm{m}$ by Alicona 3D profilometer.

\section{Microstructure and Property Characterization Techniques}

For the post-test examination, all of the metallographic specimens were cut close to the central position of the deformed specimens or within $2 \mathrm{~mm}$ distance to the fracture surface. Their longitudinal planes were under scrutiny by TEM and EBSD/TKD (Figure 1). TEM was carried out using a JEM-2100 high-resolution microscope operated at $200 \mathrm{kV}$. Both the bright-field imaging mode and selected area diffraction (SAD) were used to characterize the evolution of grain and boundary structures. TEM thin foil specimens were mechanically ground and then twin jet thinned in an electrolytic solution of 4 pet perchloric acid +96 pet alcohol at 75 V.

The microstructure and texture evolution in the as-MDF, annealed, tensile and fatigued specimens (Table I) were studied in a quantitative manner using a Zeiss AURIGA FIB-SEM workstation equipped with an EBSD detector, having the TKD capability. The main advantage of TKD over the EBSD is to offer a significantly higher spatial resolution; hence this technique was used for analyzing sub-micrometer grains in the as-MDF cp-Ti (Table I). Meanwhile, the EBSD was used to characterize those annealed specimens exhibiting a relatively large grain size. TEM thin foil specimens were used for the TKD examination and the instrument operated at $30 \mathrm{kV}$ with a step size of $50 \mathrm{~nm}$. EBSD scans were performed at $20 \mathrm{kV}$ and a range of step sizes were selected depending on the grain sizes $\left(200 \mathrm{~nm}\right.$ for $600^{\circ} \mathrm{C}$, $300 \mathrm{~nm}$ for $700{ }^{\circ} \mathrm{C}$, and $1.2 \mu \mathrm{m}$ for $800{ }^{\circ} \mathrm{C}$ annealed samples).

Micro-hardness measurements were performed on HXD-1000TM/LCD tester at a load of $0.98 \mathrm{~N}$ for 15 seconds per indent. The average value out of 10 individual measurements is presented. Again, the longitudinal plane was examined.

\section{Microstructure and Texture Analysis Based on EBSD/TKD Dataset}

To ensure the statistical rigor of the microstructure and texture characterization, a large field-of-view EBSD/TKD map was collected for each material condition. The EBSD scanning areas are $60 \times 90 \mu \mathrm{m}$ for $600{ }^{\circ} \mathrm{C}, 100 \times 150 \mu \mathrm{m}$ for $700{ }^{\circ} \mathrm{C}$, and $400 \times 600 \mu \mathrm{m}$ for $800{ }^{\circ} \mathrm{C}$ annealed samples. The number of grains under EBSD scans are greater than 1200 for $600^{\circ} \mathrm{C}, 300$ for $700{ }^{\circ} \mathrm{C}, 600$ for $800{ }^{\circ} \mathrm{C}$ samples. In terms of the tensile and fatigue samples, the number of grains under TKD scans are greater than 500 . The data analysis was carried out using HKL Technology Channel 5 and MTEX Matlab toolbox (Version 5.2.4).

The inverse pole figure (IPF) orientation maps superimposed with grain boundary characters were used to illustrate the microstructural evolution. In the IPF orientation maps, thick-black lines denote HAGBs (defined with misorientation angles of $>15 \mathrm{deg}$ ), while thin-white lines denote LAGBs with the lower threshold cut-off angle of $2 \mathrm{deg}$. The change in the fraction of LAGBs in relation to the HAGBs was used to determine the recrystallization type. Grain size distribution histogram and its lognormal distribution data fitting were used to characterize grain growth behavior.

It is known that the calculated fraction of HAGBs and the average grain size would be different if the cut-off misorientation angle of $>10 \mathrm{deg}$ was selected. Here we take an example from the grain size measurements of $600{ }^{\circ} \mathrm{C}$ annealed samples. The use of cut-off misorientation angle of $>15 \mathrm{deg}$, as adopted in the present work, resulted in the grain sizes of $0.44,1.83$, 2.16, and $2.28 \mu \mathrm{m}$ for the as-MDF, $1 \mathrm{~h}, 2 \mathrm{~h}$ and $4 \mathrm{~h}$ annealed samples at $600{ }^{\circ} \mathrm{C}$ (see Figure 11 for data illustration). By comparison, the use of $>10 \mathrm{deg}$ led to the respective grain sizes of $0.42,1.81,1.99$, and 2.05 $\mu \mathrm{m}$. Therefore, it was confirmed that the selection of cut-off misorientation angle of $>15$ deg does not affect the conclusions drawn from the present work.

The fraction of recrystallized grains was calculated on the basis of internal average misorientation angle (IAMA) maps. The grains with IAMA values of $>1$ deg were classified as deformed grains. The grains consisted of sub-grains with IAMA values of $<1$ deg but 

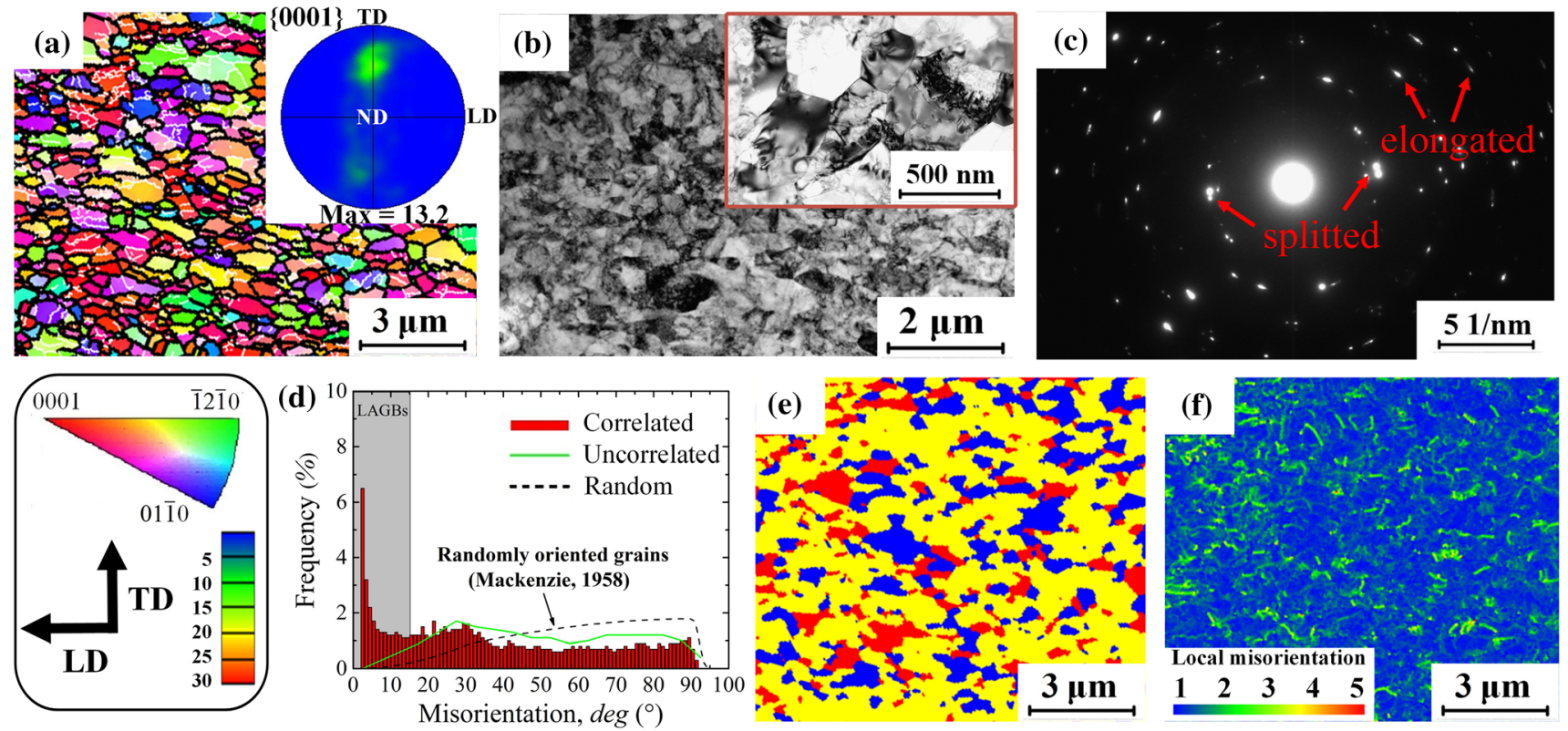

Fig. 2-As-MDF cp-Ti: (a) TKD IPF orientation map and $\{0001\}$ pole figure showing the TD-split texture, $(b)$ TEM micrograph, $(c)$ SAD pattern showing the non-equilibrium state of grain boundaries, $(d)$ grain boundary misorientation distribution indicating the presence of texture and sub-grains, (e) IAMA map showing the distribution of substructured grains (yellow) relative to the deformed (red) and recrystallized (blue) ones, and $(f)$ KAM map showing the uniformly distributed local misorientations. (d) through (f) Derived from the TKD map.

the sub-grain misorientation angle of $>1$ deg were termed as substructured ones. All the others were classified as recrystallized grains.

The local grain misorientation was calculated based on kernel average misorientation (KAM) analysis, from which the geometrically necessary dislocation (GND) density was derived. Any local misorientation angle of $>$ 2 deg was excluded to avoid the influence of sub-grains. In-grain misorientation profiles (IGMP) analysis was performed on two typical grains: one with its $c$-axis parallel to ND, while the other being randomly oriented and away from the basal texture. In order to elucidate the texture evolution in relation to dislocation slip, Schmid factor (SF) analysis was also performed.

\section{RESULTS}

\section{A. UFG Microstructure Characteristics}

The EBSD map and pole figure of the as-MDF cp-Ti are presented in Figure 2(a). The grain size was measured to be $0.44 \mu \mathrm{m}$ with aspect ratio of 2.18 . The sub-micrometer grains were distributed uniformly throughout the microstructure, proving the effectiveness of MDF process. The pole figure shows the strength of the clustering of poles, relative to that from a random distribution; hence the magnitude of the multiples of uniform density (mud) can be used to indicate the crystallographic texture. It is evident from the pole figure that the as-MDF cp-Ti had strong texture along the [0001] direction. The $c$-axis was tilted between $40 \mathrm{deg}$ and $60 \mathrm{deg}$ from the TD toward ND (denoted as TD-split texture). The basal pole intensity with the maximum density of 13.2 mud spread both within the
TD-ND plane and perpendicular to it. The TEM observation did not reveal any deformation twins (Figure 2(b)). The split diffraction spots in SAD pattern (Figure 2(c)) indicated the existence of LAGBs, while the elongated ones suggested the presence of high internal stress. Both are the typical character of grain boundaries in a non-equilibrium state. ${ }^{[5]}$

The grain boundary misorientation distribution of the as-MDF cp-Ti is shown in Figure 2(d). "Correlated" in the figure were derived from the misorientation data between neighboring points, while "Uncorrelated" were derived from the misorientation data between randomly chosen points. "Random" outlines the theoretically calculated misorientation distribution of randomly oriented grains in a polycrystal. The distribution of correlated misorientations differed from that of the uncorrelated one particularly for the LAGBs. This suggests that there was a special relationship between adjacent grains, i.e., the presence of sub-grains in the present circumstance. Furthermore, the uncorrelated distribution differed from the random distribution (Figure 2(d)), indicating a preferred crystallographic orientation.

The IAMA and KAM maps are presented in Figures 2(e) and (f). The as-MDF cp-Ti had a large number of substructured grains $(\sim 60$ pct in yellow), with the rest being recrystallized (blue) and deformed (red) grains. The three characteristic grains were distributed uniformly in the as-MDF microstructure (Figure 2(e)). The KAM map in Figure 2(f) showed an evenly distributed local misorientation, with the high intensity regions corresponding to those deformed grains (red in Figure 2(e)). The average GND density was derived as $\rho=1.41 \times 10^{15} \mathrm{~m}^{-2}$, indicating that the as-MDF cp-Ti contained high stored energy. By using 

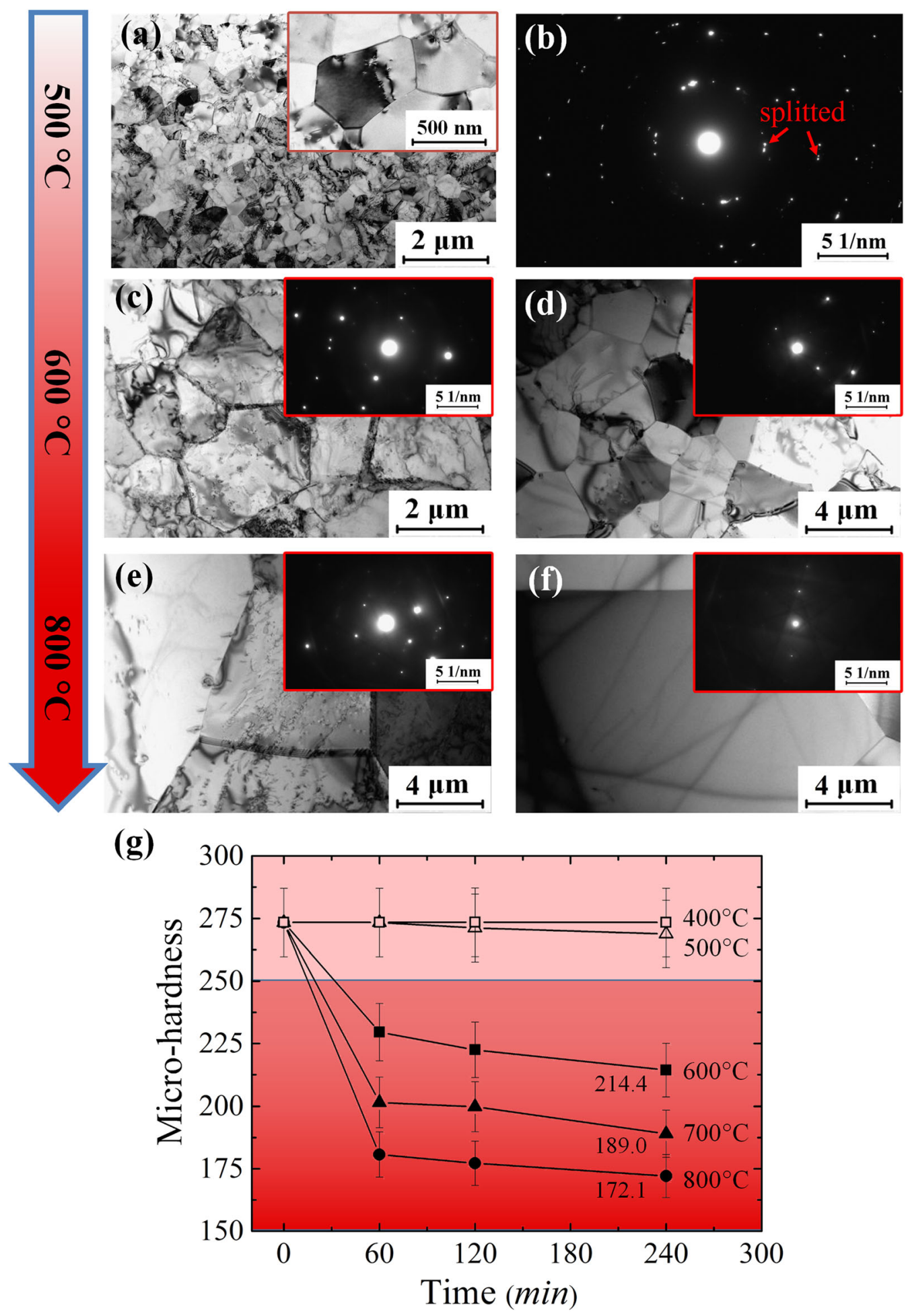

Fig. 3-Bright-field TEM micrographs and SAD patterns of post-annealed MDF cp-Ti: $(a)$ and $(b) 4 \mathrm{~h} \mathrm{at} 500{ }^{\circ} \mathrm{C},(c) 2 \mathrm{~h}$ at $600{ }^{\circ} \mathrm{C},(d) 4 \mathrm{~h}$ at $600{ }^{\circ} \mathrm{C},(e) 2 \mathrm{~h}$ at $800{ }^{\circ} \mathrm{C},(f) 4 \mathrm{~h}$ at $800{ }^{\circ} \mathrm{C}$, and $(g)$ micro-hardness changes as a function of annealing time.

shear modulus of $G=40 \mathrm{GPa}$ and Burgers vector of $b$ $=0.295 \mathrm{~nm}$ for $\mathrm{cp}-\mathrm{Ti}^{[11]}$ the driving force $p$ for recrystallization was calculated to be $2.45 \times 10^{6} \mathrm{~J} / \mathrm{m}^{3}$ based on the relation ${ }^{[12]}$.

$$
p=\frac{1}{2} \rho G b^{2} .
$$




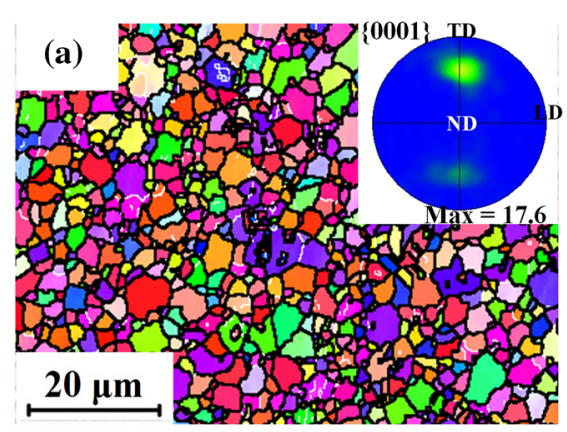

(d)

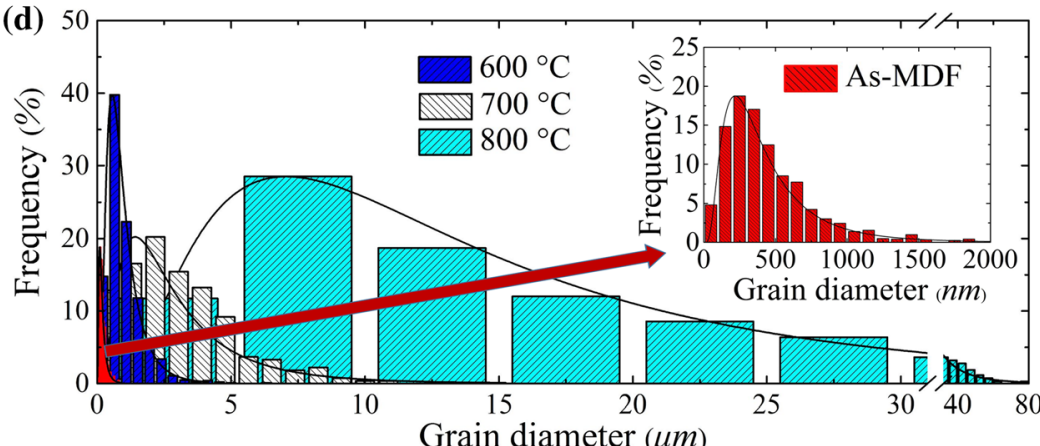

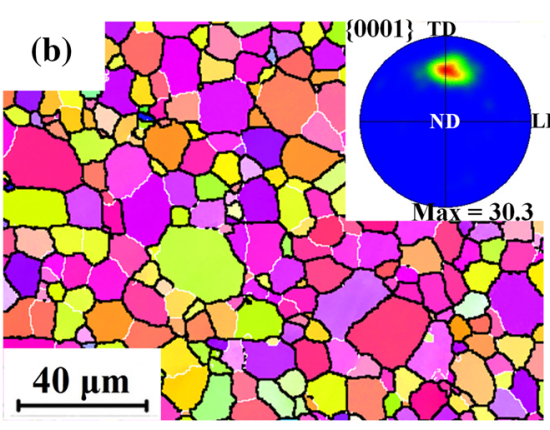

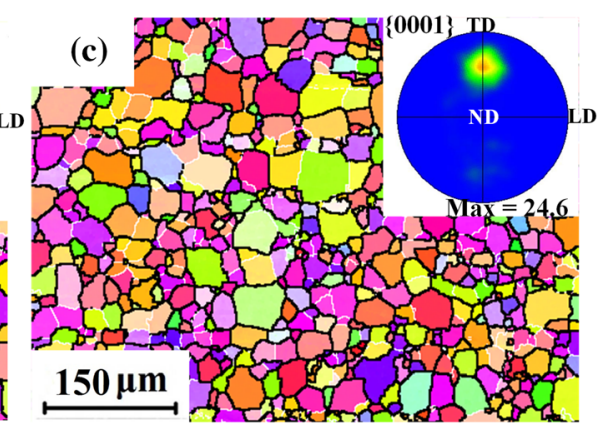

(e)

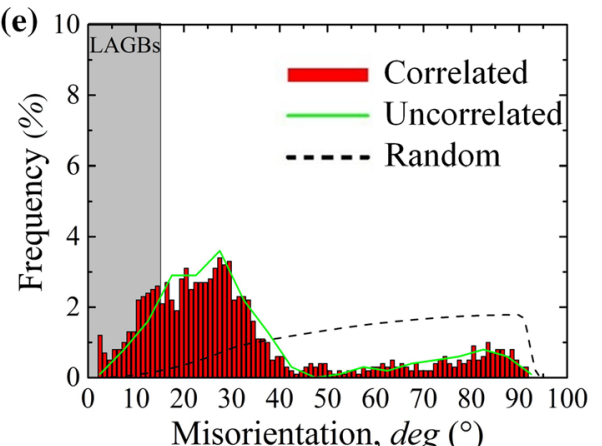

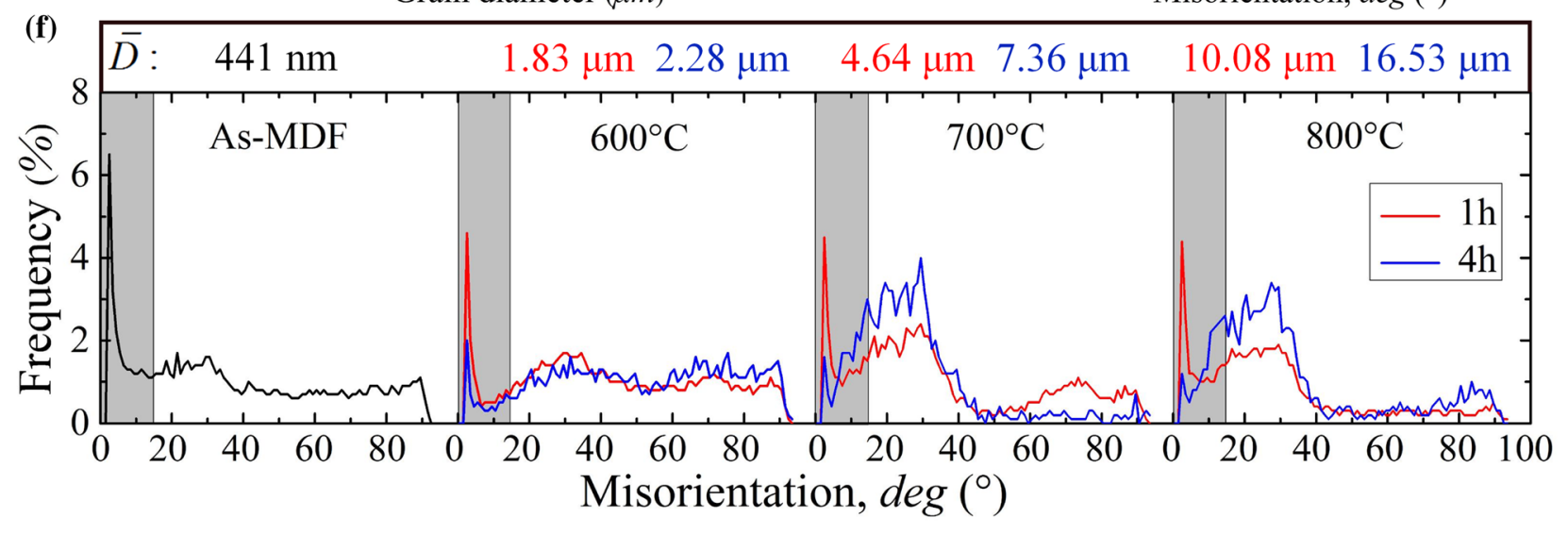

Fig. 4-High-temperature annealed MDF cp-Ti: $(a)$ through $(c)$ EBSD orientation maps and pole figures obtained from 4 h annealed specimens with (a) $600{ }^{\circ} \mathrm{C}$, (b) $700{ }^{\circ} \mathrm{C}$, and (c) $800{ }^{\circ} \mathrm{C}$, (d) their grain size distribution and lognormal curve fitting, (e) grain boundary misorientation distribution of $4 \mathrm{~h}$ annealed specimens at $800^{\circ} \mathrm{C}$, and $(f)$ evolution of the correlated misorientation distribution histogram.

This suggests that the non-equilibrium grain boundaries in the as-MDF cp-Ti are prone to recrystallization when certain conditions are met.

\section{B. Annealing Behavior of Post-dynamic Recrystallized UFG Microstructure}

Annealing heat treatments were performed at low temperatures $\left(400{ }^{\circ} \mathrm{C}\right.$ and $500{ }^{\circ} \mathrm{C}$, up to 4 hours) to assess thermal stability of the UFG microstructure. A representative TEM micrograph and SAD pattern, obtained from the MDF cp-Ti after annealing at 500 ${ }^{\circ} \mathrm{C}$ for 4 hours, are shown in Figures 3(a) and (b). The average grain size of this sample was determined to be $0.49 \mu \mathrm{m}$ by linear intercept method, and thus the grain growth was marginal. The SAD pattern obtained from this specimen showed much less elongated diffraction spots, comparing Figures 3(b) with 2(c). This indicates that low-temperature annealing caused relaxation of the high internal stress. Indeed, the annealed specimen showed less dislocation contrast (Figure 3(a)) compared with that in the as-MDF condition (Figure 2(b)), suggesting the annihilation of dislocations by recovery. This agreed well with little effect of annealing on the micro-hardness; $273.4 \pm 8.6$ for the as-MDF condition, while $268.8 \pm 9.0$ for 4 hours annealed specimen at 500 ${ }^{\circ} \mathrm{C}$ (Table I). Note that all the other specimens within this low-temperature group did not show any sign of grain growth under TEM examination (not shown for brevity) and their micro-hardness values were similar to that of the as-MDF cp-Ti (Figure 3(g)). Overall, the low-temperature annealing was difficult to trigger recrystallization.

In terms of the high-temperature annealing $\left(600{ }^{\circ} \mathrm{C}\right.$, $700{ }^{\circ} \mathrm{C}$ and $800{ }^{\circ} \mathrm{C}$, up to $4 \mathrm{~h}$ ), grain growth occurred and the grain size became larger with the increasing temperature and time. Representative TEM micrographs together with SAD patterns obtained from 600 
${ }^{\circ} \mathrm{C}$ and $800{ }^{\circ} \mathrm{C}$ annealed specimens are shown in Figures 3(c) through (f). Both the split diffraction spots and elongated ones were not observed, indicating that recrystallization caused reduced LAGBs and internal stress relaxed to a greater extent. For the annealing time of 2 hours, some dislocation tangles remained at the grain interior $\left(600{ }^{\circ} \mathrm{C}\right.$ in Figure $3(\mathrm{c})$ and $800{ }^{\circ} \mathrm{C}$ in Figure 3(e)). By contrast, the grain interior appeared to be transparent due to the reduced dislocation contrast, when the annealing time increased to 4 hours $\left(600^{\circ} \mathrm{C}\right.$ in Figure 3(d) and $800{ }^{\circ} \mathrm{C}$ in Figure 3(f)). The specimen subjected to 4 hours annealing at $800{ }^{\circ} \mathrm{C}$ is typical of fully recrystallized microstructure; grain boundaries became well-defined (i.e., transition into an equilibrium state) and the individual dislocation lines were distinguishable in the grain interior (Figure 3(f)). These observed dislocation changes and grain growth agreed well with the reduced micro-hardness (Figure 3(g)).
The EBSD was used to reveal the textural evolution and provide quantitative description of the microstructural evolution due to high-temperature annealing. Representative EBSD orientation maps are shown in Figures 4(a), (b) and (c), for 4 hours annealed MDF cp-Ti at $600{ }^{\circ} \mathrm{C}, 700{ }^{\circ} \mathrm{C}$ and $800{ }^{\circ} \mathrm{C}$, respectively. Compared with the as-MDF condition (Figure 2(a)), the size of grains increased with the increasing temperature and their shape became more near-equiaxed. The grain size basically followed lognormal distribution and no bimodal size distribution can be seen in Figure 4(d). This means that recrystallization happened uniformly throughout the microstructure. The average grain size increased from $0.44 \mu \mathrm{m}$ (as-MDF condition), to $2.28 \mu \mathrm{m}$ $\left(600^{\circ} \mathrm{C}\right), 7.36 \mu \mathrm{m}\left(700^{\circ} \mathrm{C}\right)$ and $16.53 \mu \mathrm{m}\left(800^{\circ} \mathrm{C}\right)$ after 4 hours annealing, respectively. The kinetics of grain growth during annealing has been derived and described in "Appendix A"; the growth exponent of $n=0.15,0.29$
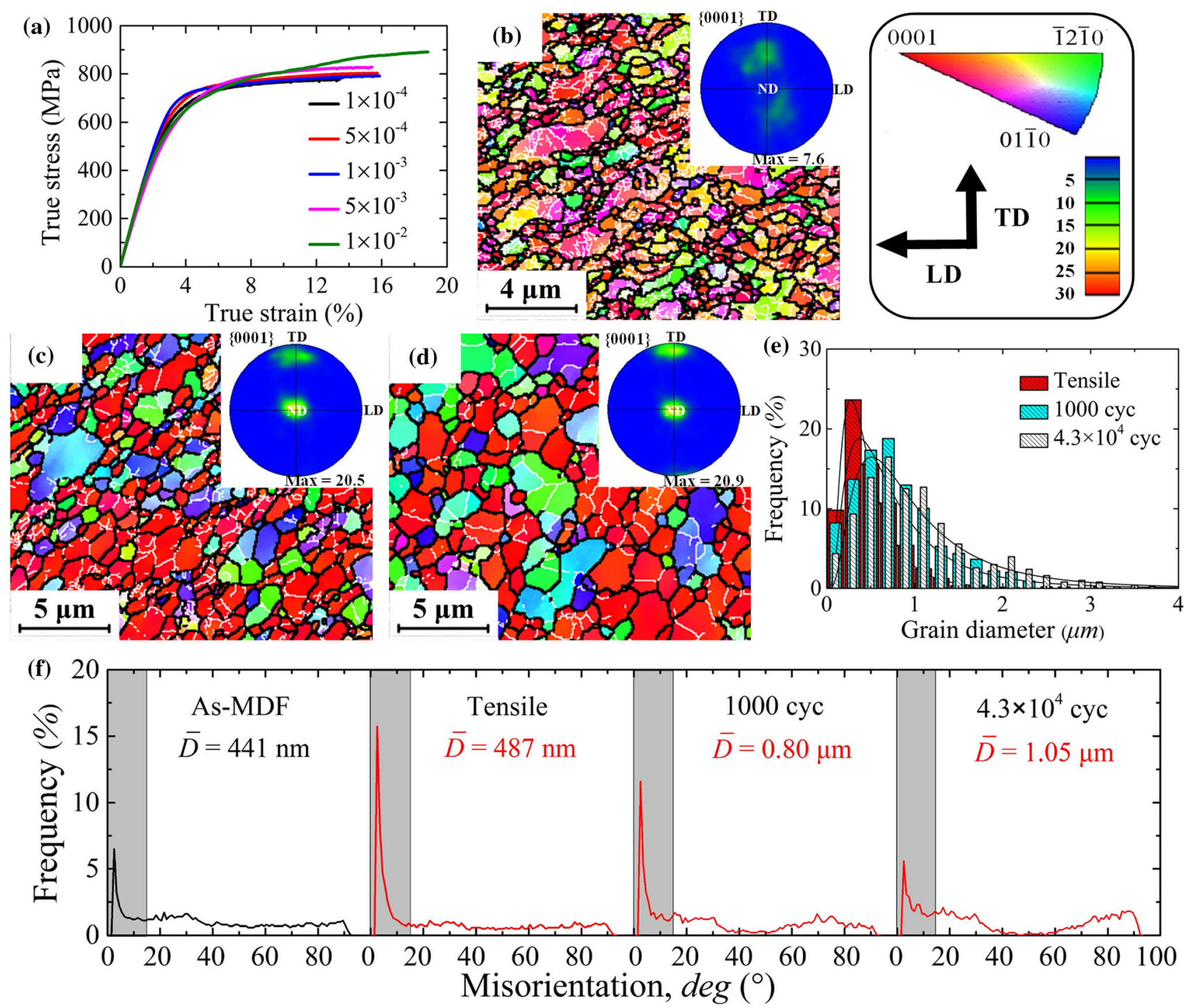

Fig. 5-(a) True stress-strain tensile curves obtained at RT under difference strain rates, (b) TKD IPF orientation map and $\{0001\}$ pole figure on the tensile loaded specimen with strain rate of $1 \times 10^{-4} \mathrm{~s}^{-1},(c)$ and $(d)$ IPF orientation maps and pole figures for fatigued specimens, after 1000 and $4.3 \times 10^{4}$ cycles, respectively, $(e)$ grain size distribution histograms and $(f)$ evolution of the misorientation distribution histograms. 
Table II. Summary of Tensile Properties of MDF cp-Ti, as Well as the Measured Grain Size and Micro-hardness at the End of the Test

\begin{tabular}{lccccc}
\hline $\begin{array}{l}\text { Tensile Strain } \\
\left(\mathrm{s}^{-1}\right)\end{array}$ & $\begin{array}{c}\text { Rate } \\
(\mathrm{MPa})\end{array}$ & $\begin{array}{c}\text { Yield Strength } \\
(\mathrm{MPa})\end{array}$ & $\begin{array}{c}\text { Ultimate Tensile Strength } \\
(\mathrm{Pct})\end{array}$ & $\begin{array}{c}\text { Elongation to Failure } \\
(\mu \mathrm{m})\end{array}$ & $\begin{array}{c}\text { Hain Size } \\
(\mathrm{HV})\end{array}$ \\
\hline $1 \times 10^{-4}$ & 552 & 702 & 27 & 0.49 & $272.5 \pm 10.4$ \\
$5 \times 10^{-4}$ & 553 & 705 & 28 & N/A & $273.5 \pm 9.9$ \\
$1 \times 10^{-3}$ & 559 & 705 & 27 & 0.52 & $270.5 \pm 8.1$ \\
$5 \times 10^{-3}$ & 551 & 733 & 24 & N/A & $271.5 \pm 8.6$ \\
$1 \times 10^{-2}$ & 554 & 758 & 24 & 0.49 & $275.5 \pm 11.3$ \\
\hline
\end{tabular}

and $0.33\left(600\right.$ to $\left.800{ }^{\circ} \mathrm{C}\right)$ and activation energy of $Q=$ $241.7 \mathrm{~kJ} / \mathrm{mol}$ were obtained.

It is evident from the pole figures (the inset of Figures 4(a) through (c)) that the MDF deformation texture kept more or less the same, with the maximum basal pole intensity appearing within $40 \mathrm{deg}$ to $60 \mathrm{deg}$ from the TD to ND. The basal pole intensity at the upper hemisphere tended to be strengthened and the maximum intensity increased from 13.2 mud (as-MDF condition in Figure 2(a)), to 17.6, 30.3 and 24.6 mud, after $4 \mathrm{~h}$ annealing at $600{ }^{\circ} \mathrm{C}, 700{ }^{\circ} \mathrm{C}$ and $800{ }^{\circ} \mathrm{C}$. The intensity change is likely to be a consequence of reduced grain boundary proportion caused by the grain growth. Note that all the other specimens within this high-temperature group had the similar basal pole position (not shown for brevity), indicating the lack of lattice rotation during the grain growth.

The misorientation distribution histogram obtained from the 4 hours and $800{ }^{\circ} \mathrm{C}$ annealed specimen is shown in Figure 4(e). Several features are worthwhile to be noted. First, the difference between the correlated and uncorrelated misorientations was significantly reduced compared with the as-MDF condition (Figure 2(d)), indicating that the transition from LAGBs to HAGBs occurred concurrently with the grain growth; a characteristic feature of continuous recrystallization. ${ }^{[13]}$ Second, the distribution of correlated and uncorrelated misorientations differed evidently from the random distribution (Figure 4(e)). This can be attributed to the 30 deg aggregation phenomenon.

Based on the correlated misorientations, it was found that the fraction of LAGBs reduced from 24.9 pct in the as-MDF cp-Ti to 7.6 pct in annealed condition $\left(4\right.$ hours at $\left.600{ }^{\circ} \mathrm{C}\right)$, and then increased to 19.6 pct $\left(4\right.$ hours at $\left.800{ }^{\circ} \mathrm{C}\right)$. This inverse relationship indicates that the 30 deg aggregation phenomenon was enhanced at higher temperatures. The development of 30 deg aggregation accompanied with the grain growth across all the annealed specimens is collectively presented in Figure 4(f). At $600{ }^{\circ} \mathrm{C}$, the 30 deg aggregation was relatively limited even though the size of grains increased to $2.28 \mu \mathrm{m}$ after 4 hours annealing. With the temperature increase to $700{ }^{\circ} \mathrm{C}$ and $800{ }^{\circ} \mathrm{C}$, there was incipient $30 \mathrm{deg}$ aggregation after 1 hour, and the peak became stronger after 4 hours (Figure 4(f)). Note that the $30 \mathrm{deg}$ aggregation phenomenon was reported many times (e.g., References
14-16) and claimed as a recrystallization feature for hcp metals. ${ }^{[17]}$

The 30 deg aggregation was exclusively attributed to the formation of coincidence site lattice (CSL) boundaries with potentially low energies corresponding to a $27.8 \mathrm{deg}$ rotation around the $c$-axis. ${ }^{[15,16]}$ Unfortunately, there was little experimental evidence to support the interpretation, albeit some molecular dynamics results. ${ }^{[18]}$ Note that the latest version of HKL Channel 5 software does not incorporate the database required to analyze the CSL boundaries in hep metals. Thus, the axis/angle values as well as $\Sigma$-values for cp-Ti obtained from Reference 19 were inputted into the software and the Brandon criterion ${ }^{[20]}$ was used to categorize CSL boundaries. It was found that the CSL boundaries of $\Sigma 11$ b,$\Sigma 17$ c, $\Sigma 19$ c, $\Sigma 22$ a,$\Sigma 23$ b, $\Sigma 23$ c were extremely low in all the specimens. We also confirmed that the most frequently mentioned $\Sigma 13 \mathrm{a}$, that had been claimed as the reason for 30 deg aggregation in equal channel angular pressed (ECAP) $\mathrm{Mg},{ }^{[15]}$ did not show any significant increase after annealing at $800^{\circ} \mathrm{C}$ for 4 hours. This suggests that the 30 deg peak (Figure 4(f)) in the annealed MDF cp-Ti cannot be attributed to the CSL boundaries.

\section{Strain-Induced Microstructure and Texture Evolution}

The tensile curves in true stress and strain, under a range of strain rates are presented in Figure 5(a). The presence of stress fluctuation behavior during hot deformation (i.e., up and down ${ }^{[21]}$ or stress peak ${ }^{[22]}$ when plotting the stress-strain curve) has been recognized as the DRX characteristics. This applies to different deformation modes including tensile, ${ }^{[23,}$ 24] compressive, ${ }^{[25]}$ and torsion. ${ }^{[26]}$ Therefore, the absence of stress fluctuation in Figure 5(a) indicates that dynamic recrystallization did not occur in the MDF cp-Ti under monotonic loading. In addition, the tensile properties did not show any significant rate dependence (Table II). The micro-hardness and grain size also had little difference under the selected strain rates. To this end, the specimen subjected to the lowest tensile rate of 1 $\times 10^{-4} \mathrm{~s}^{-1}$ was selected for a comparative analysis with the cyclic loaded specimen $(R=-1$ and $14 \mathrm{~Hz}$ fatigued at RT).

The IPF misorientation map and pole figure from the tensile specimen are shown in Figure 5(b). The basal texture became much weaker with the maximum 

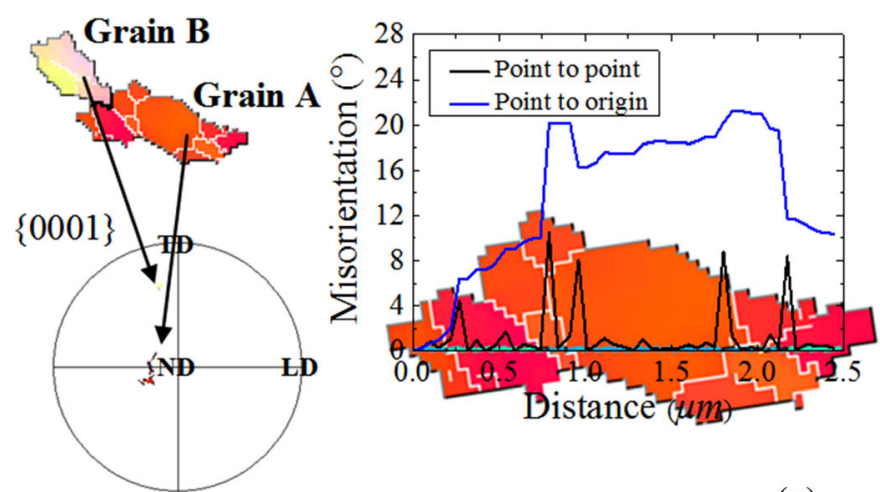

(a)

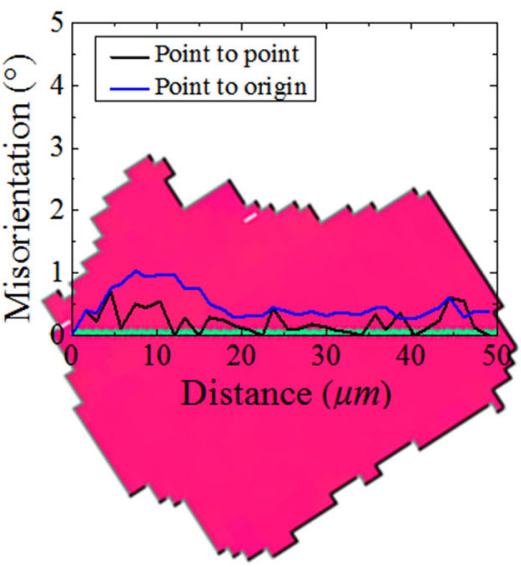

(b)

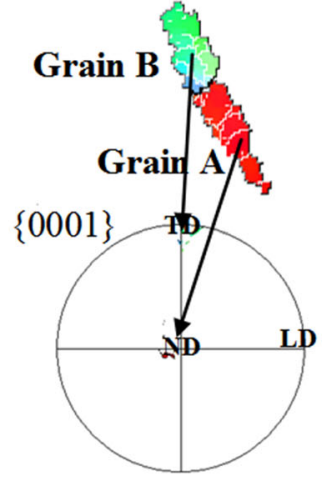

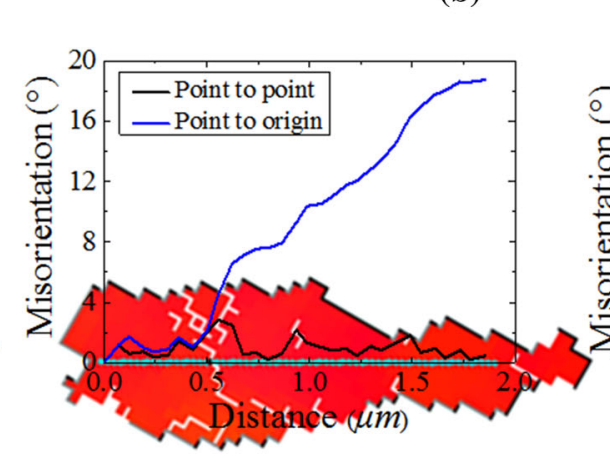

(c)
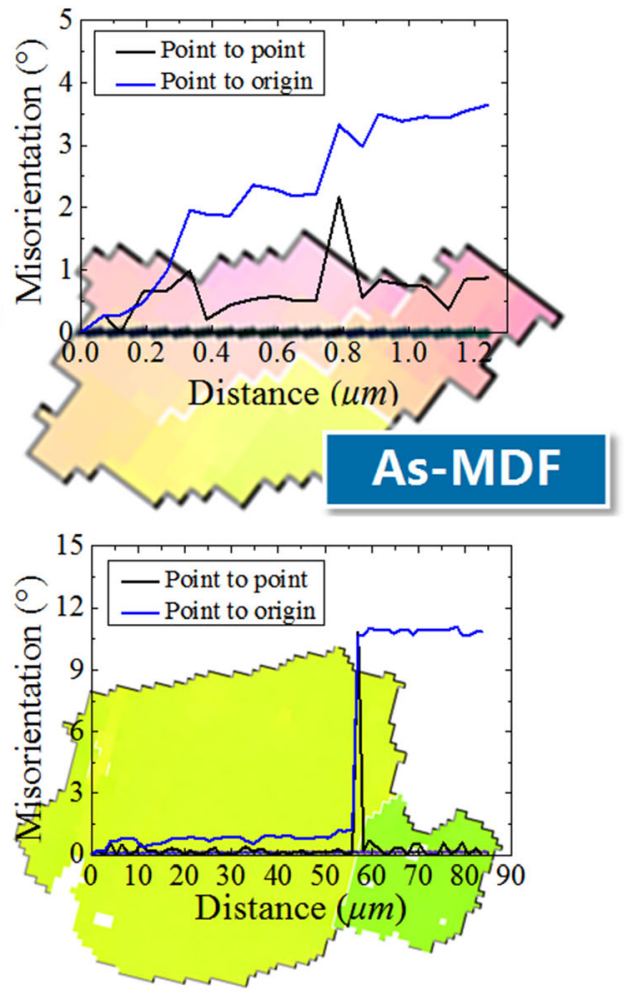

Annealing
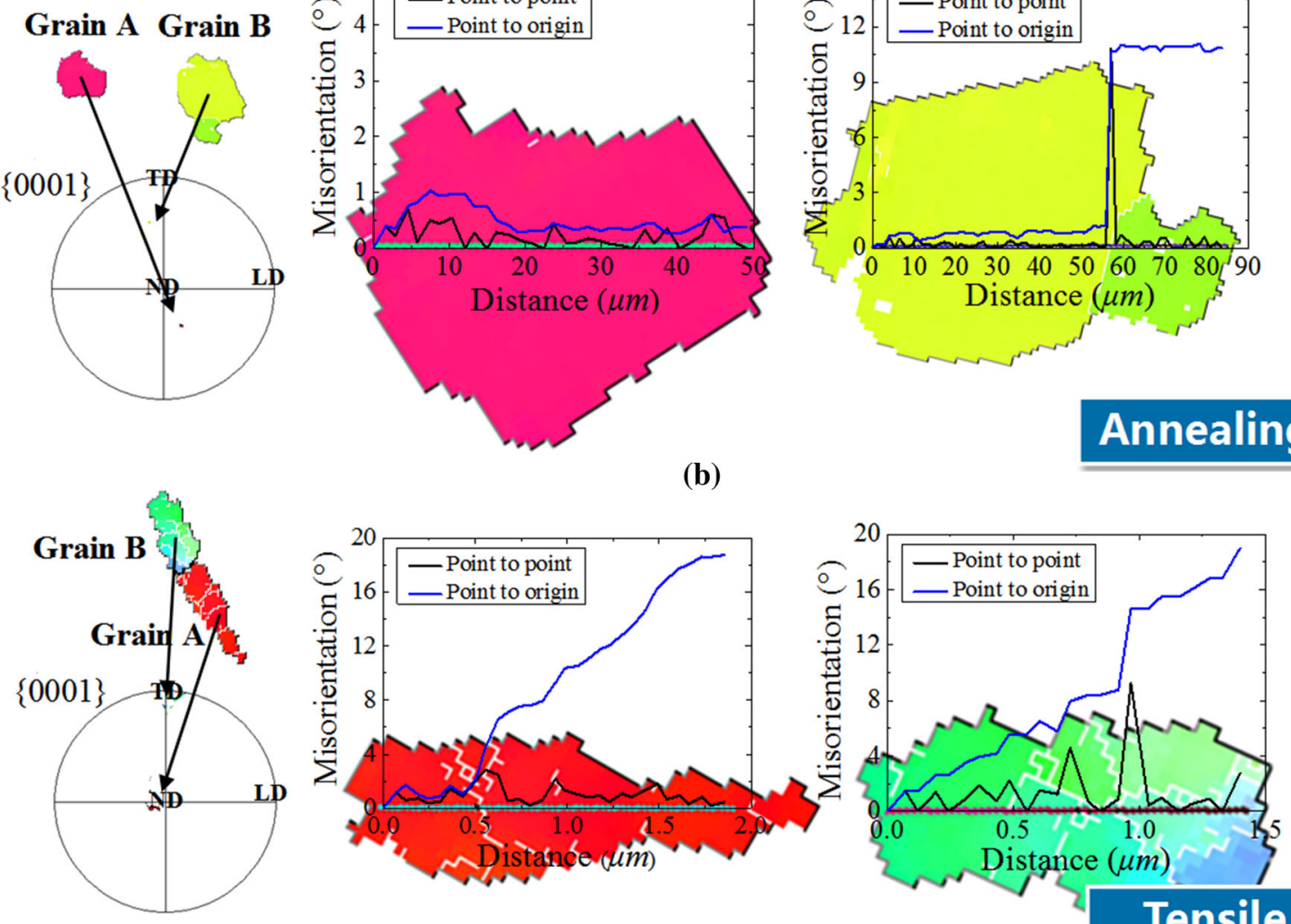

Tensile

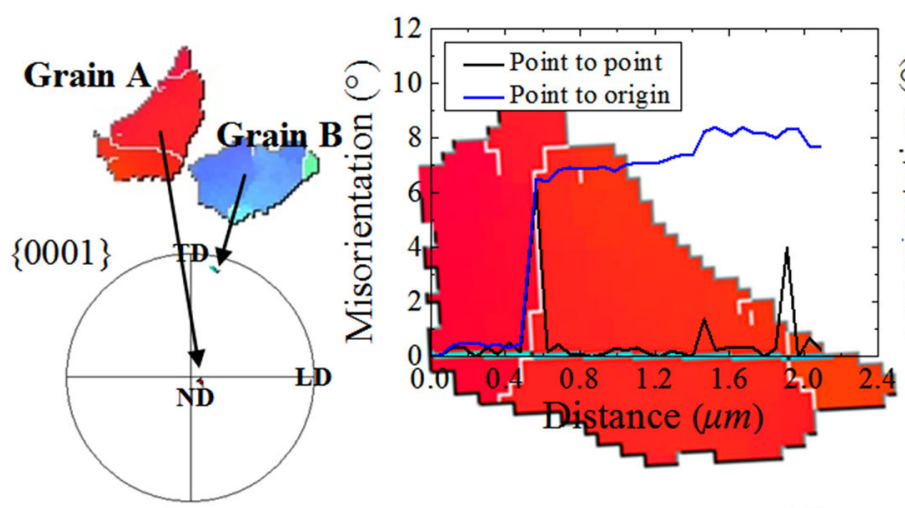

(d)

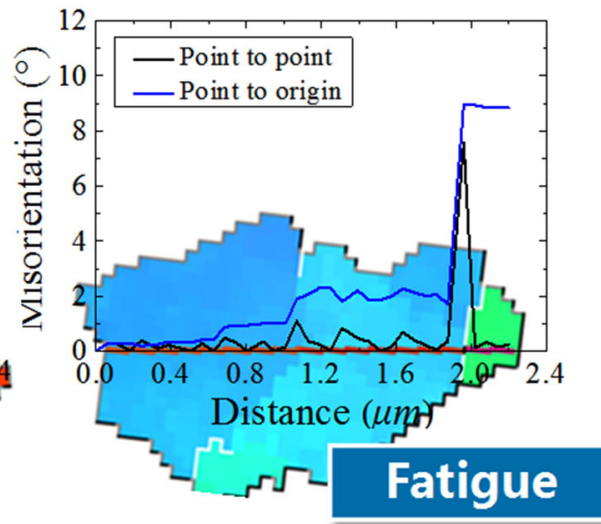


4 Fig. 6-In-grain misorientation profiles of two typical grains (one from that with the $c$-axis aligned with the ND, the other from that with the $c$-axis far away from the ND): $(a)$ as-MDF, $(b)$ annealed at $800{ }^{\circ} \mathrm{C}$ and $4 \mathrm{~h},(c)$ tensile deformed with deformation rate of $1 \times$ $10^{-4} \mathrm{~s}^{-1}$ at RT, and $(d)$ fatigued until $4.3 \times 10^{4}$ cycles at RT. The metallographic specimens were taken within $2 \mathrm{~mm}$ distance to the fracture surface.

intensity reduced to 7.6 mud (against 13.2 mud in the as-MDF condition) and the location kept the same, although there was some orientation spread. The high level of stress (hence the high plastic strain) was likely to induce the activation of more slip systems including $\langle c+$ a) mode. Therefore, the orientation spread to both ND and LD (Figure 5(b)) during monotonic tensile may be related to the activation of pyramidal $\langle c+a\rangle$ slips, as suggested in the work ${ }^{[27]}$ for magnesium alloys.

By comparison, a dramatic texture change was found in the fatigued specimens, Figures 5(c) (1000 cycles) and (d) $\left(4.3 \times 10^{4}\right.$ cycles $)$. Their $\{0001\}$ pole figures show that the $c$-axis tended to be orientated along the ND with the highest intensity of 20.5 and 20.9 mud, respectively. A weaker texture component close to the TD was also developed as a result of fatigue loading. By further analyzing the IPF misorientation maps (Figures 2(a), 5b through (d)) with the deviation threshold of $\leq 20 \mathrm{deg}$ with respect to the [0001] direction, the proportion of $\{0001\}$ texture component was measured to be 6.9 pct, 8.3 pct and 49.5 pct for the as-MDF, tensile and fatigued $\left(4.3 \times 10^{4}\right.$ cycles $)$ specimens, respectively. Note that a small number of fatigue cycles (i.e., less than 1000) seemed to be sufficient to trigger the texture evolution. Further fatigue loading of up to $4.3 \times$ $10^{4}$ did not cause any significant textural difference. Recall that the high-temperature annealing only strengthened the basal pole intensity but without affecting its location. This makes the fatigue-induced recrystallization in MDF cp-Ti particularly intriguing, especially the formation of a much sharper basal pole intensity around the ND.

Figure 5(e) shows that the grain size distribution followed the lognormal distribution and no bimodal characteristic was observed after the fatigue loading. The average grain size increased to $0.80 \mu \mathrm{m}$ (1000 cycles) and $1.05 \mu \mathrm{m}\left(4.3 \times 10^{4}\right.$ cycles $)$. The grain growth in fatigued MDF cp-Ti was accompanied by the change in the fraction of LAGBs (Figure 5(f)). There was a moderate increase of LAGBs from 24.9 pct in the as-MDF condition to 34.9 pct after 1000 cycles, followed by a decrease to 24.1 pct after $4.3 \times 10^{4}$ cycles. The initial increased fraction of LAGBs was probably due to the dislocation activation associated with fatigue loading. With further fatigue loading, the driving force for recrystallization seemed to be enhanced and the stored energy at some point was sufficiently high to trigger the recrystallization, hence a transition from LAGBs to HAGBs. Considering that the fraction of LAGBs increased to 43.5 pct due to monotonic loading (Figure 5(f)), this may lead us to conclude that the accumulated monotonic plastic strain energy cannot trigger the recrystallization and grain growth in the MDF cp-Ti. The presence of $30 \mathrm{deg}$ aggregation in the fatigued MDF cp-Ti but not in the tensile one (Figure 5(f)), provides another evidence to suggest the fatigue-induced recrystallization.

An aggregation peak at around $80 \mathrm{deg}$ to $90 \mathrm{deg}$ in the fatigued MDF cp-Ti was not observed in the tensile specimen, but there was some hint in the annealed one (Figure 4(e)). The $85 \mathrm{deg}$ aggregation in hcp $\mathrm{Mg}$ has been generally related to the formation of $\{10 \overline{1} 2\}\langle 10 \overline{1} 1\rangle$ tension twinning. However, there was no measurable twins in the present MDF cp-Ti according to our EBSD/ TKD analysis. Hence, such an aggregation peak at around $80 \mathrm{deg}$ to $90 \mathrm{deg}$ was probably caused by the texture evolution or grain growth.

\section{In-grain Misorientation Profiles (IGMP)}

The discrete pole figures and in-grain misorientation profiles (IGMP) of selected grains (marked by capital letters of A and B) are presented in Figures 6(a) through (d). Grain A represents those grains with the $c$-axis aligned with the ND, while grain B is typical of those with a random orientation. Four conditions were considered: as-MDF in Figure 6(a), annealed $\left(800{ }^{\circ} \mathrm{C}\right.$ and 4 hours) in Figure 6(b), tensile deformed $\left(1 \times 10^{-4}\right.$ $\left.\mathrm{s}^{-1}, \mathrm{RT}\right)$ in Figure $6(\mathrm{c})$, fatigue loaded $\left(4.3 \times 10^{4}\right.$ cycles, RT) in Figure 6(d). In these figures, the black curve represents the misorientation data relative to the previous point (point to point), which can be used to determine the presence of LAGBs within the grain. The blue curve represents the misorientation data relative to the first point (point to origin), indicating the accumulated change of misorientations, i.e., the degree of plastic deformation.

For the as-MDF cp-Ti, there were many peaks in the black curve with misorientation angles of $2 \mathrm{deg}$ to $12 \mathrm{deg}$ in grain A, suggesting the presence of sub-grains with the grain separated by LAGBs. For the blue curve, the monotonic angle change in each sub-grain was up to 5 deg, indicating that the interior of sub-grains had large internal stress. By comparison, grain $\mathrm{B}$ with its $c$-axis away from the ND showed a much fewer LAGBs with misorientation angles of typically below $2 \mathrm{deg}$, and the monotonic change of the blue curve was up to $3 \mathrm{deg}$. These IGMP characteristics of grains A and B indicate that the high stored energy was accumulated in the as-MDF cp-Ti (especially grain A), hence being susceptible to recovery or recrystallization.

After annealing, the selected grain A did not contain any sub-grain (no peak with misorientation angles in the range of $2 \mathrm{deg}$ to $15 \mathrm{deg}$ for the black curve), and there was only one LAGB with the misorientation angle of 10 deg in grain B (Figure 6(b)). The state of more complete recrystallization in grain $\mathrm{A}$ seems to be consistent with the higher stored energy in grain A compared to grain B in the as-MDF condition (Figure 6(a)). An alternative explanation about the remained LAGB (10 deg misorientation angle) in grain B is that this boundary was just about to finish the sub-grain coalescence and would migrate into an HAGB if the annealing time was increased. Meanwhile, the monotonic change of the blue curves for both grains was less than 1 deg 
(Figure 6(b)), confirming that high internal stress was relaxed and they were fully recrystallized. This agrees with the TEM micrograph and SAD pattern as presented in Figure 3(f).

After tensile deformation, the increased number of peaks (the black curve) having misorientation angles of $\geq 2$ deg (LAGBs) can be seen for both grains (Figure 6(c)). Furthermore, there was a significant monotonic increase of the blue curves up to around 20 deg for both grains A and B. These IGMP features indicate that grains were subjected to a heavy plastic deformation under tensile loading. However, there was no evidence to suggest the presence of recovery or recrystallization.

After fatigue loading, the number of LAGBs (peaks with misorientation angle of $2 \mathrm{deg}$ to $15 \mathrm{deg}$ for the black curve) in both grains A and B was reduced (Figure 6(d)), when compared with the as-MDF (Figure 6(a)) and tensile (Figure 6(c)) conditions. The monotonic change of the blue curve within each sub-grain was found to be up to $2 \mathrm{deg}$. This suggests that the high internal stress would have been relaxed during fatigue loading. Therefore, the post-dynamic recrystallized $\mathrm{cp}-\mathrm{Ti}$ processed by $\mathrm{MDF}$ is prone to recrystallization during fatigue loading. Comparing with the annealed condition (Figure 6(b)), grain A in fatigued condition (Figure 6(d)) exhibited the higher misorientation angles within the sub-grains. This means that the grains were not in the state of complete recrystallization after fatigue loading. This was probably owing to the material hardening and softening that occurred alternately during the fatigue of MDF cp-Ti, typical of that in the dynamic recrystallization process. ${ }^{[28]}$

\section{DISCUSSION}

\section{A. Continuous Static and Dynamic Recrystallization ( $c S R X$ and $c D R X$ )}

The post-dynamic recrystallized $\mathrm{cp}$-Ti processed by MDF was subjected to isothermal annealing, RT tensile loading under a wide range of strain rates, and RT fully reversed high-cycle fatigue loading under $14 \mathrm{~Hz}$. It is evident from the TEM and EBSD/TKD observations (Figures 3(a), (c), (e) and 4(a) through (c)) that the UFG grains grew rapidly at temperatures of $600{ }^{\circ} \mathrm{C}$ and above. At lower annealing temperatures limited grain growth was found, but there was clear evidence to suggest the relaxation of high internal stress (Figure 3(b)) as well as dislocation re-arrangement especially at the grain boundary regions (the inset in Figure 3(a)). These microstructural observations agreed well with the micro-hardness measurement (Figure 3(g)). All of the findings above suggest that MDF cp-Ti has a thermally stable microstructure (up to $400{ }^{\circ} \mathrm{C}$ ). By comparison, the microstructural stability of MDF cp-Ti under RT cyclic loading is far inferior. The UFG grains grew to 0.80 and $1.05 \mu \mathrm{m}$ due to 1000 and $4.3 \times 10^{4}$ cycles, respectively (Figure 5(f)). The fatigue-induced grain growth is interesting as the underlying mechanism to trigger the mechanical grain growth cannot be readily understood, especially considering that insignificant grain growth was found under the slow tensile rate (Figures 5(a) and (b)).

Previous studies on nanocrystalline materials (e.g., $\mathrm{Al}^{[29]}, \mathrm{Ni}-\mathrm{Fe}$ and $\mathrm{Co}-\mathrm{P}$ alloys ${ }^{[30]}$ ) revealed mechanical grain growth under RT tensile loading. But it is worthwhile to note that their conclusions were drawn from the presence of abnormal grain growth, leading to a bimodal microstructure with large grain size up to a few hundreds of nanometers compared to the initial size of 12 to $90 \mathrm{~nm}$. Also, the as-deposited nanocrystalline materials have intrinsic difference in dislocation density and structure as compared to the as-MDF ones (i.e., the bulk nanocrystalline materials fabricated by SPD). Such a difference would impact the post-recrystallization behavior.

In the present work, the observed grain growth in MDF cp-Ti (initial grain size of $0.44 \mu \mathrm{m}$ ), triggered by annealing and fatigue but not by tensile loading, was characterized by a lognormal distribution shift toward larger grain sizes (Figures 4(d) and 5(e)). No evidence was revealed for abnormal grain growth. This is consistent with the previous work on nanocrystalline $\mathrm{Ni}$ under tensile loading ${ }^{[31]}$ and on ECAP and MDF cp-Ti under fatigue loading. ${ }^{[10]}$ The grain size distribution resemblance between annealed and fatigued cp-Ti seems to suggest that a thermally assisted dislocation process already occurred at RT.

Figure 7(a) summarizes the change of average GND density with reference to the as-MDF condition. For comparison purposes, the equivalent time duration for the tensile and fatigue tests was estimated from the strain rate of $1 \times 10^{-4} \mathrm{~s}^{-1}$ and the frequency of $14 \mathrm{~Hz}$, respectively. The average GND density increased from $1.41 \times 10^{15}$ to $1.72 \times 10^{15} \mathrm{~m}^{-2}$ due to tensile loading, but decreased remarkedly by two orders of magnitude to $3.33 \times 10^{13} \mathrm{~m}^{-2}$ after $4 \mathrm{~h}$ annealing at $800{ }^{\circ} \mathrm{C}$ (Figure 7(a)). Note that there was a continuous decrease in LAGBs (Figure 4(f)) to form the recrystallized grains. Hence, cSRX was the controlling mechanism for the grain growth due to annealing. The increased GND density in tensile loaded MDF cp-Ti is expected, because there was a large amount of plastic strains according to the tensile curve (Figure 5(a)).

By contrast, a moderate decrease in the GND density $\left(8.21 \times 10^{14} \mathrm{~m}^{-2}\right)$ was found in the fatigued MDF cp-Ti (Figure 7(a)). In addition, the fraction of LAGBs increased and then decreased with the increasing fatigue cycles (Figure 5(f)). Thus, the controlling mechanism for the fatigue-induced grain growth is believed to be cDRX. The reason why the GND density drop in the fatigued MDF cp-Ti being much less compared to the annealed counterpart can be attributed to the dynamic superposition of hardening by dislocation generation and softening by recrystallization.

For the as-MDF cp-Ti, the IAMA map in Figure 2(e) illustrates a mixture of substructured grains as the majority, recrystallized and deformed ones as the minority. The fraction of each characteristic grain type was calculated based on the IAMA maps obtained from the representative samples after tensile, fatigue and annealing tests. The data comparison with the as-MDF 


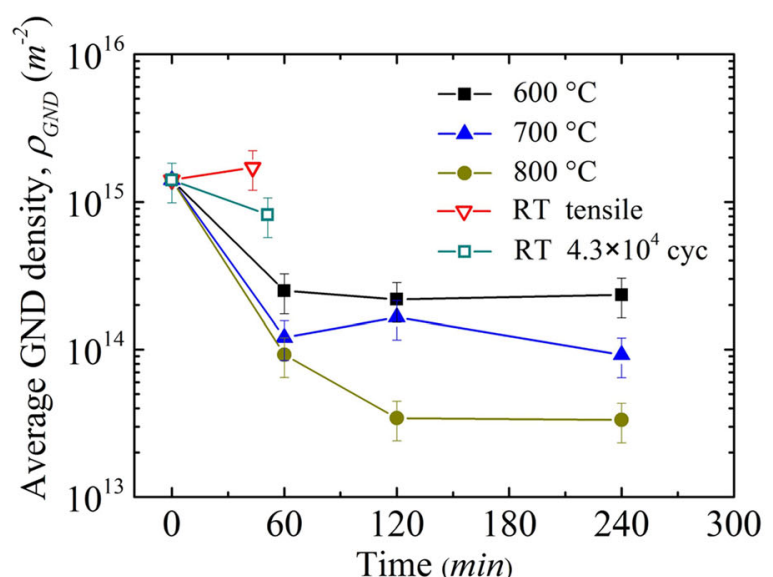

(a)

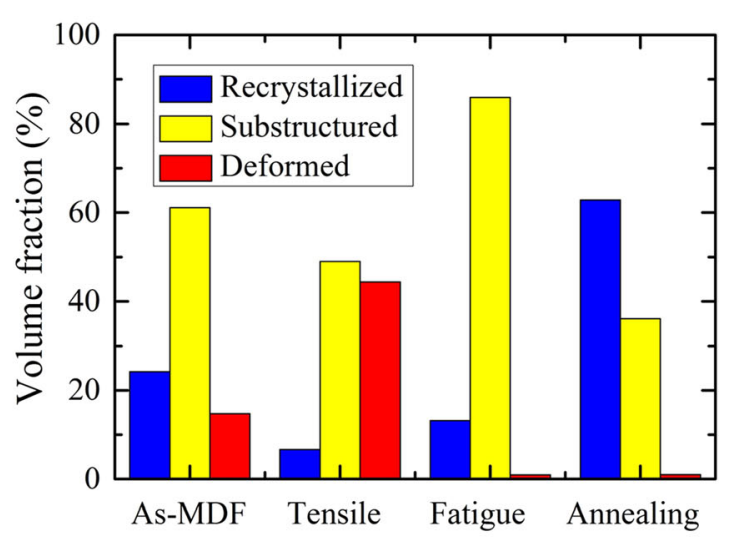

(b)

Fig. 7- Quantitative description of $(a)$ the average GND density and $(b)$ the volume fraction of recrystallized, substructured and deformed grains due to annealing and loading. Samples selected for the analysis were the same as those in Figs. 6(a) through (d).

condition are shown in Figure 7(b). For the annealed MDF cp-Ti, the proportion of deformed grains reduced to almost zero, while that of recrystallized ones increased remarkedly. Meanwhile, there was a 20 pct decrease in the fraction of substructured grains compared to the as-MDF cp-Ti. By contrast, the fatigued MDF cp-Ti showed a dramatic increase in the fraction of substructured grains $(\sim 85 \mathrm{pct})$ at the expense of the recrystallized and deformed ones. Therefore, the IAMA analysis is proved as an effective means to distinguish the cDRX from cSRX. The last but not the least, the increased fraction of deformed grains in tensile MDF cp-Ti accompanied with the reduced fractions for the other two types provides further evidence that recrystallization did not occur during the monotonic loading.

$\mathrm{Li}^{[32]}$ pointed out that extra dislocations in the nanocrystalline grain boundary can initiate mechanical grain growth. This has thus been believed as the reason why mechanical grain growth can take place in nanocrystals often having a non-equilibrium grain boundary structure, but not in microcrystals. Since the present UFG cp-Ti was processed by MDF, the resulting grain boundary is deemed to be in a non-equilibrium state with extra dislocations. It then becomes interesting to interrogate whether the dislocation activity could play a certain role in fatigue-induced recrystallization and grain growth.

A theoretical calculation of shear stress $\sigma_{x y}$ required to remove dislocations from the pure grain boundary can be calculated using the relation proposed $\mathrm{in}^{[32]}$ :

$$
\sigma_{x y}=a G b / 2 \pi h(1-v),
$$

where shear modulus $G=40 \mathrm{GPa}$, Burgers vector $b=$ $0.295 \mathrm{~nm}$ and Poisson's ratio $v=0.34$ are used for cp-Ti. ${ }^{[11,33]}$ It was assumed that the free dislocations were parallel to $z$ axis and the dislocation wall was in the $y z$ plane. The magnitude of $a$ in Eq. [2] is equal to 0.8 being independent of the number of free dislocations, if more than 3 dislocations are removed from an equilibrium boundary. ${ }^{[32]}$ According to the TEM micrograph, the dislocation spacing $h$ was estimated as 5 to $10 \mathrm{~nm}$ for the as-MDF cp-Ti. The stress required is thus calculated as $\sigma_{x y}=455.3$ to $227.6 \mathrm{MPa}$ according to Eq. [2]. In addition, for a non-equilibrium grain boundary, i.e., the existence of extra free dislocations, the required stress would be reduced to a very low level $\left(\sigma_{x y}=34.1\right.$ to 17.1 $\mathrm{MPa}$ ) because of the magnitude of $a$ being as low as $0.06 .^{[32]}$ Therefore, the dislocation activity is very likely to play a certain role in MDF cp-Ti during the fatigue loading, although the applied stress level (stress amplitude of $280 \mathrm{MPa}$ ) is much lower than the yield strength (552 MPa, Table II). Also, there was TEM evidence to support the dislocation activity by revealing both the multiple slip and cross-slip characteristics in post-fatigued MDF cp-Ti (Figures 8(a) and (b)). To this end, the fatigue triggered cDRX and grain growth phenomenon in MDF cp-Ti can be satisfactorily explained.

But it is still not clear why a large tensile plastic strain induced by the monotonic loading, even with the very low strain rate of $1 \times 10^{-4} \mathrm{~s}^{-1}$, cannot trigger such a mechanical grain growth. Since the UFG microstructure in MDF cp-Ti was proved to be thermally stable up to $400{ }^{\circ} \mathrm{C}$, it is difficult to attribute primarily to the temperature effect caused by $14 \mathrm{~Hz}$ fatigue loading. Infrared thermograph technique was used to monitor the surface temperature under high-cycle fatigue loading at $40 \mathrm{~Hz},{ }^{[8]}$ where the maximum surface temperature was measured to be below $50{ }^{\circ} \mathrm{C}$. However, one should not neglect that the low thermal conductivity of cp-Ti $(24.5 \mathrm{~W} / \mathrm{mK})$ is about one-fourth of $\mathrm{Fe}(94 \mathrm{~W} / \mathrm{mK})$ and $\mathrm{Ni}(106 \mathrm{~W} / \mathrm{mK})$. This may make the cp-Ti easier to get heated by cyclic loading, and hence promoting the dislocation activity. In fact, there have been two experimental work to show that at very low temperature (thereby thermally activated processes should be inoperative) the grain growth process of UFG $\mathrm{Cu}(-50$ $\left.{ }^{\circ} \mathrm{C}\right)^{[34]}$ and cp-Ti $\left(-200{ }^{\circ} \mathrm{C}\right)^{[10]}$ under fatigue loading can 
be restricted. Therefore, the present work does not permit us to rule out completely the thermally activated process of cDRX.

\section{B. Fatigue-Induced Texture Change}

Accompanied with the fatigue-induced grain growth, a different but strong basal texture was developed, having a significant number of grains with the $c$-axis aligned with the ND (Figures 5(c) and (d)). This suggests that there was a significant lattice rotation. The previous work on AZ31B Mg alloy ${ }^{[9]}$ also found the fatigue-induced crystallographic texture change, but both the deformation condition and lattice rotation direction were different to the present work. First, we applied a low stress amplitude $R=-1$ fatigue, that is distinctly different to $R=0.1$ as adopted in the work. ${ }^{[9]}$ Second, we observed the lattice rotation within the TD-ND plane, i.e., always being perpendicular to the load axis, whereas the lattice rotation was found to be toward the fatigue loading direction in previous work.

It is worth noting that the grain growth and texture evolution as revealed from the TKD results (Figures 5(c) and (d)) are consistent with the previous in situ neutron diffraction results. ${ }^{[10]}$ It is obvious that a much larger sampling area was used in the neutron diffraction measurement. It has already been confirmed that the micro-texture information based on the TKD analysis was consistent with the completely different relative peak intensities among all the diffraction peaks as revealed by the two neutron detector banks located at \pm 90 deg relative to the incident beam. More details can be found in Reference 10. Also, the good consistency across the two techniques proved that the MDF processing can produce a homogenous microstructure. Thus, the fatigue-induced texture change in MDF cp-Ti is repeatable with good consistency.

Although both the dislocation slip and twinning can cause crystal reorientation, it is less likely to activate deformation twins in small sized grains. ${ }^{[35]}$ The twinning to slip transition occurred with grain size refinement from 19 to $5 \mu \mathrm{m}$ in $\mathrm{Mg}{ }^{[36]}$ In addition to the intrinsic nature of MDF cp-Ti (grain size of $0.44 \mu \mathrm{m}$ ), there are two fatigue test conditions that do not favor the twinning. First, the applied stress amplitude of 280 MPa (only half of the yield strength) would be too low to activate twinning. In a previous work on $\mathrm{cp}-\mathrm{Ti}^{\left[{ }^{[37]}\right.}$ the critical resolved shear stresses (CRSSs) to activate twinning were very close to the yield strength. Second, even if a small amount of twinning deformation did occur during the tensile phase, the subsequent loading reversal to the compressive phase $(R=-1)$ would favor the detwinning ${ }^{[38]}$ Note that both the TEM and EBSD/TKD observations (Figures 5(c), (d) and 8) confirmed the absence of deformation twins. In sum, the fatigue-induced texture change should not be attributed to the twinning activation in MDF cp-Ti.

The study on the microstructure evolution during high-cycle fatigue of a Mg-6Zn-1Mn alloy also revealed the relationship between the texture evolution and DRX ${ }^{[8]}$ Unfortunately, the authors did not provide any plausible explanations about their experimental results, although the possibility of twinning was ruled out. Hence, the present work represents the first study to explain the fatigue-induced texture evolution in bulk nanocrystalline hep metal. On the other hand, the grain boundary sliding of UFG grains can also contribute to the accommodated plastic deformation, causing the texture change. ${ }^{[39]}$ Since the lattice rotation is essentially to accommodate further deformation, it is possible to predict the evolution of grain orientation by examining the slip mode. In other words, the grain rotation occurs for the sake of making the crystal orientation reach the optimal position to activate the dislocation slip.

In terms of dislocation slip, the major deformation modes of cp-Ti are basal and prismatic $\langle a\rangle$ slips and their CRSSs were estimated as 49 and $37 \mathrm{MPa}$, respectively. ${ }^{[37]}$ By contrast, pyramidal $\langle a\rangle$ and $\langle c+a\rangle$ slips are rarely activated at RT as their CRSSs are much higher. ${ }^{[40]}$ It seems that the activation probability of basal and prismatic $\langle a\rangle$ slips are almost equal for $\mathrm{cp}-\mathrm{Ti}$, which is distinctly different from the more widely studied $\mathrm{Mg}$ (15 MPa for the former, but $67 \mathrm{MPa}$ for the latter $\left.{ }^{[41]}\right)$. This means that the knowledge gained regarding the texture evolution in $\mathrm{Mg}$ during loading might not be applicable to cp-Ti. Therefore, it is necessary to examine the dislocation slip mode in order to accurately predict the texture evolution during fatigue loading of MDF cp-Ti.

Under monotonic tensile loading, the slip plane and direction tended to be parallel to the load axis, whereas the slip plane and direction tended to be perpendicular
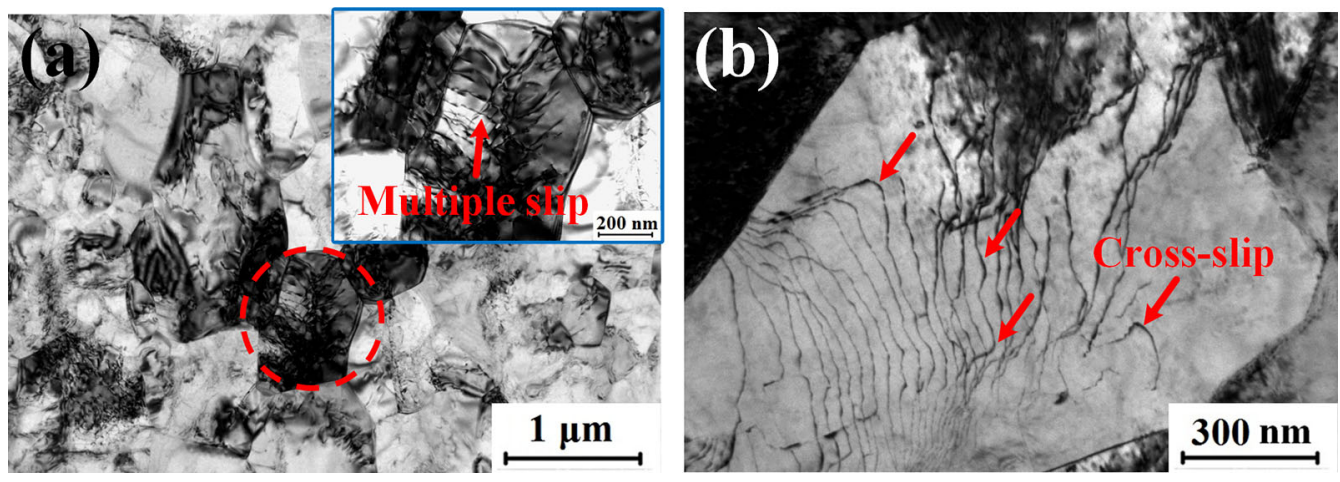

Fig. 8-Multiple slip in $(a)$ and cross-slip in $(b)$ for the fatigued MDF cp-Ti after $4.3 \times 10^{4}$ cycles. 


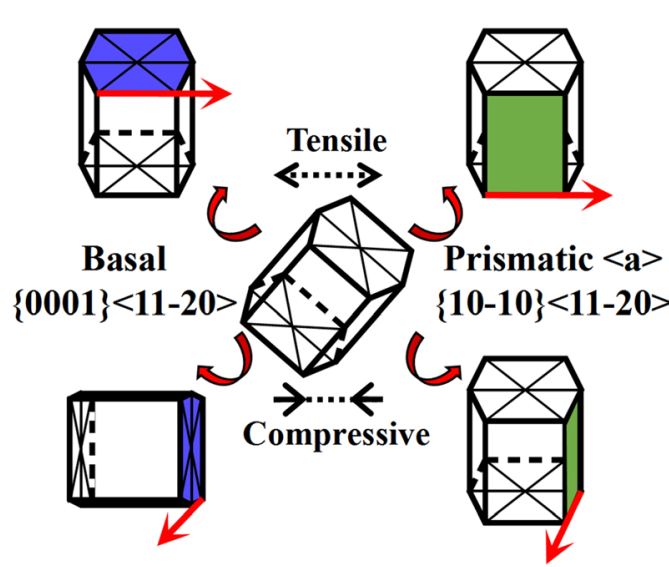

(a)

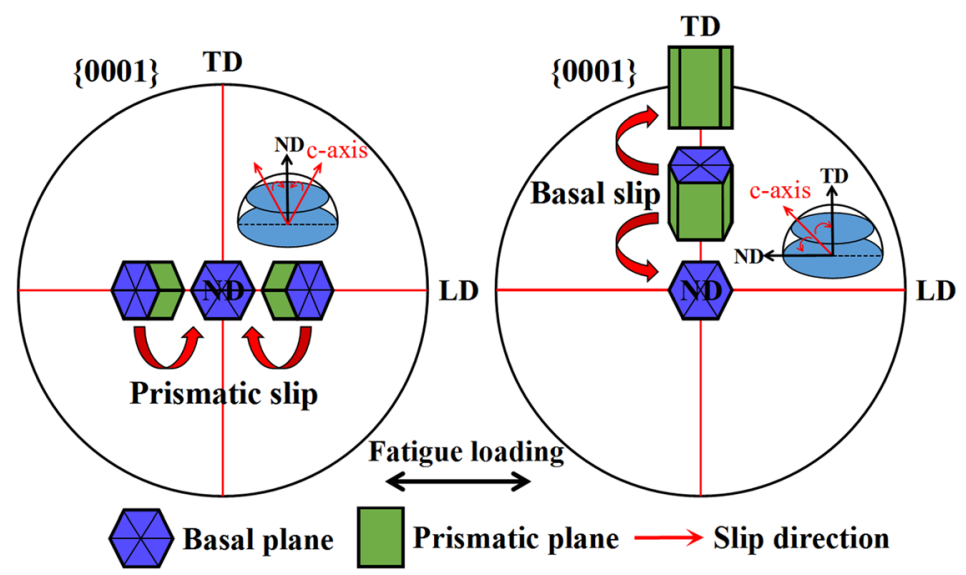

(b) (c)

Fig. 9-Schematic diagrams: (a) lattice rotation when basal $\{0001\}\langle 11 \overline{2} 0\rangle$ and prismatic $\{10 \overline{1} 0\}\langle 11 \overline{2} 0\rangle$ slips are activated for cp-Ti under tensile and compressive loading, $(b)$ and $(c)$ the corresponding texture change under fatigue loading.

to the load axis under compression. ${ }^{[42]}$ Both are controlled by the CRSS law to accommodate plastic deformation, and the grain rotation behavior is illustrated schematically in Figure 9(a). Under tensile loading, the activation of both the basal and prismatic $\langle a\rangle$ slip would make the $c$-axis perpendicular to the load axis. However, the basal $\langle a\rangle$ slip would cause the $c$-axis parallel to the load axis, while the prismatic $\langle a\rangle$ slip makes it become perpendicular.

Figure 10(a) shows the IPF map superimposed with 3D grain orientation diagram for the post-fatigued cp-Ti. According to the Schmid law the orientation of each grain defines the most probable slip systems. Two typical grain groups (A and $\mathrm{B}$ ) were selected. The group $\mathrm{A}$ has the $c$-axis nearly perpendicular to the fatigue loading direction (LD) and the SFs of prismatic $\langle a\rangle$ slip (0.46 and 0.47) are much higher than that of basal $\langle a\rangle$ slip (0.26 and 0.16$)$. This indicates that the prismatic $\langle a\rangle$ slip was predominant in the grains. Thus, grains belonging to group A would rotate around their $c$-axis and kept their $c$-axis being perpendicular to LD under $R$ $=-1$ fatigue, as schematically shown in Figure 10(b).

On the other hand, a few grains/sub-grains were located in a more favorable orientation for the activation of basal $\langle a\rangle$ slip, namely, group B in Figure 10(b). The micromechanical modeling of monotonic loading of $\mathrm{cp}-\mathrm{Ti}^{[43]}$ showed that the yield strength obtained under compression was always higher than that under tension. This probably led to the fact that when the $c$-axis of those grains (group B) was rotated toward perpendicular to LD due to the activation of basal $\langle a\rangle$ slip (i.e., orientation similar to that for group A), the prismatic $\langle a\rangle$ slip then became predominant in the following fatigue cycles. A similar transition of predominant slip system from basal to prismatic ${ }^{[44]}$ were also reported by the plasticity analysis of texture development in $\mathrm{Mg}$ during extrusion. Thus, the transition from basal $\langle a\rangle$ to prismatic $\langle a\rangle$ slips in cp-Ti is probably the reason why the present $R=-1$ fatigue did not cause a symmetric/ reversible effect on grain rotation.
The corresponding SF maps (stress direction along LD) for the basal and prismatic $\langle a\rangle$ slip are shown in Figures 10(c) and (d), respectively. It is evident that prismatic $\langle a\rangle$ slip appears to be predominant in fatigued MDF cp-Ti. The average SFs for the basal and prismatic $\langle a\rangle$ slips derived from the distribution histograms in the as-MDF condition (not shown for brevity) are 0.17 and 0.44 , while those are 0.21 and 0.43 for the fatigue sample (the insets of Figures 10(c) and (d)) respectively. Thus, the activation of prismatic $\langle a\rangle$ slip is much higher than that of the basal slip. With the increase of fatigue cycles, most grains rotated to the stable direction with their $c$-axis perpendicular to the load axis due to the activation of prismatic $\langle a\rangle$ slip (Figures 9(a) and 10(b)). Accordingly, the polar projection of most grains converged to the TD-ND plane in $\{0001\}$ pole figure under fatigue, as schematically shown in Figure 9(b). In addition, according to the Schmid law of Figure 9(a), tension causes $\{10 \overline{1} 0\}$ to be parallel to LD, while compression causes $\{11 \overline{2} 0\}$ to be parallel to LD. Ultimately, this caused the final texture with their $\{10 \overline{1} 0\}$ or $\{11 \overline{2} 0\}$ being parallel to the LD direction, as shown in Figure 10(e).

It is worth noting that the activation of prismatic $\langle a\rangle$ slip along LD could not cause the $c$-axis rotation within the TD-ND plane. Since the last two forging directions for the as-MDF cp-Ti were perpendicular to ND and TD planes, the combined effect of compressive residual stress and the resolved shear stress perpendicular to LD (caused by Poisson ratio effect) could activate the dislocation slip. Hence, the SFs (stress direction along ND) were also calculated. The average SFs of the basal and prismatic $\langle a\rangle$ slips for the as-MDF cp-Ti were calculated as 0.39 and 0.24 , while those were 0.21 and 0.22 for the fatigued $\mathrm{cp}-\mathrm{Ti}$. The favorable orientation for basal $\langle a\rangle$ slip in the as-MDF cp-Ti may be attributed to the inclination of around $40 \mathrm{deg}$ to $50 \mathrm{deg}$ in the orientation of basal planes from ND toward TD, as schematically shown in Figure 9(c). In addition, stacking fault energies (SFEs) for basal and prismatic planes 


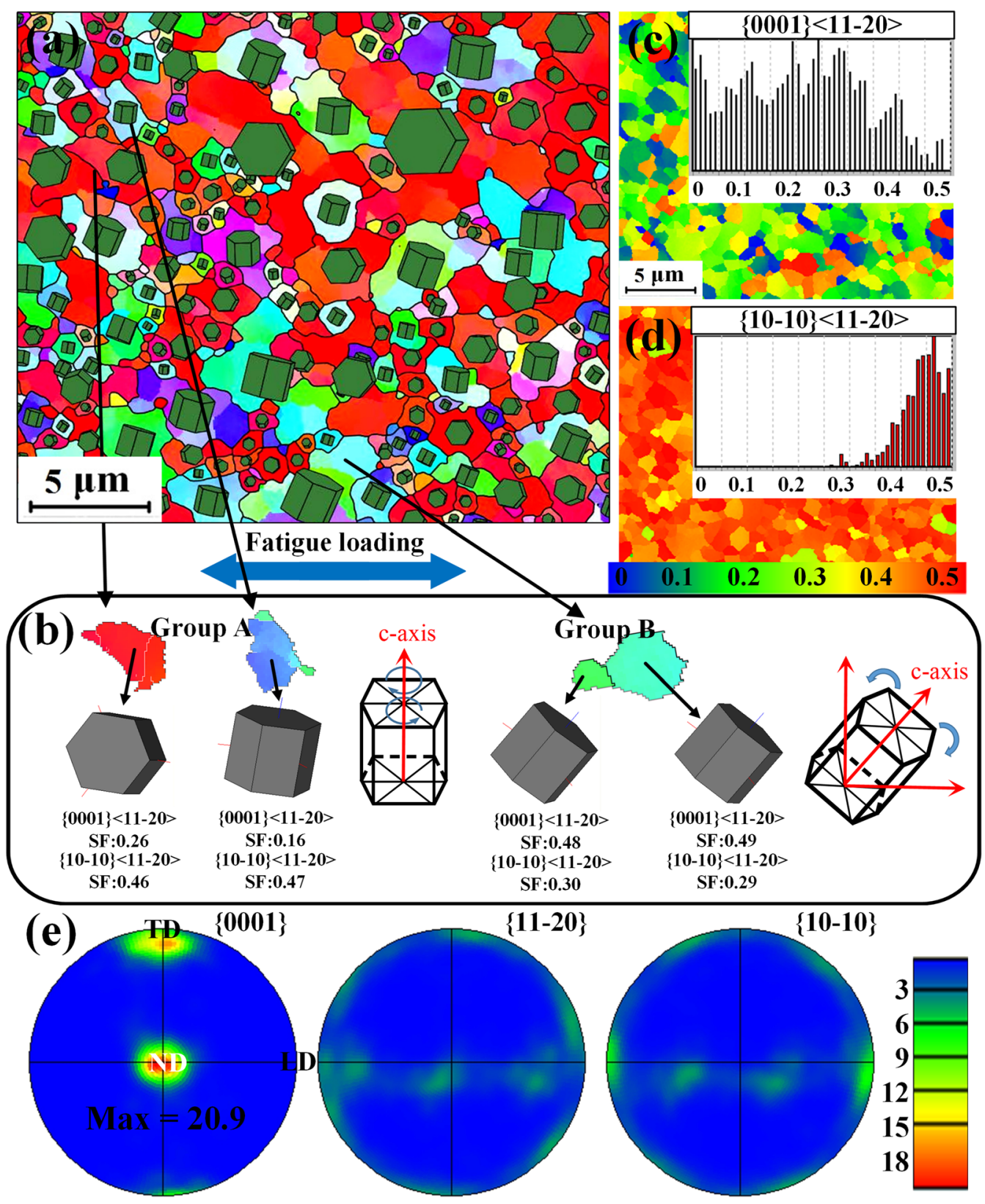

Fig. 10 - Schmid factor (SF) maps and corresponding distribution histograms of basal and prismatic $\langle a\rangle$ slip systems of the sample after fatigue loading for $4.3 \times 10^{4}$ cycles: $(a)$ the IPF map superimposed with 3D orientation diagram of each grain, $(b)$ schematic of the grain reorientation trend during fatigue loading for the typical grains, (c) SF of basal $\langle a\rangle$ slip system, (d) SF of prismatic $\langle a\rangle$ slip system, and (e) pole figures.

were reported to be 300 and $150 \mathrm{~mJ} / \mathrm{m}^{2}$ for $\mathrm{Ti}^{[45]}$ The higher SFE of the basal plane may induce cross-slip more easily (Figure 8(b)), which could enhance dynamic recovery. On the other hand, the lower SFE of prismatic slip promotes the dislocation density increase, resulting in the difficulty of dislocation slip on the prismatic plane with the progress of deformation. Therefore, the formation of texture with the $c$-axis parallel to the ND and TD in the fatigued MDF cp-Ti is likely to be attributed to the activation of basal $\langle a\rangle$ slip perpendicular to LD. Note that the texture evolution from $\{0001\}$ TD-split texture to ND basal texture observed during differential speed rolling of cp-Ti was reported in the work, ${ }^{[46]}$ and this phenomenon was also attributed to the lattice rotation caused by basal slip activity.

According to the crystal plasticity theory, the slip systems seem to be hardly activated during high-cycle fatigue loading because of the low applied stress, i.e., only half of the yield strength. However, in the present case, the grain growth-induced material softening and temperature rise (low thermal conductivity of $\mathrm{cp}$-Ti) during fatigue should not be neglected. Such a material softening behavior can facilitate the activation of dislocation slips. Furthermore, the superimposed residual compressive stress on the applied stress on the TD and ND planes, induced by the MDF process, can also 
contribute to the critical stress to trigger the activation of dislocation slips.

In sum, the fatigue-induced lattice reorientation was attributed to the gradual lattice rotation by the activation of prismatic $\langle a\rangle$ slip parallel to LD (Figure 9(b)) and the activation of basal slip perpendicular to LD (Figure 9(c)). In addition, the grain boundary sliding and cDRX dominated grain growth may also serve as auxiliary mechanisms for the dislocation slip-induced grain rotation during fatigue loading.

\section{CONCLUSIONS}

The post-dynamic recrystallization behavior of cp-Ti processed by MDF, was studied under the following three conditions: annealing, RT monotonic tensile loading, and $R=-1$ high-cycle fatigue loading. The main conclusions are summarized as follows:

1) Recrystallization and uniform grain growth occurred at high-temperature $\left(\geq 600^{\circ} \mathrm{C}\right)$ annealing and $R=-1$ fatigue. No evidence was revealed for the abnormal grain growth. By contrast, RT tensile loading with the low strain rate cannot trigger the grain growth.

2) 30 deg aggregation occurred concurrently with the grain growth, but there was no evidence to suggest its correlation with the characteristic CSL boundaries.

3) The recrystallization texture as revealed in the annealed MDF cp-Ti appeared to be enhanced in terms of the intensity but without affecting its location compared to the as-MDF condition. The mechanism behind was confirmed as cSRX.

4) The fatigue-induced texture evolution and grain growth was controlled by cDRX and there was clear evidence to suggest the dislocation activity. The formation of a different but strong texture in fatigued MDF cp-Ti can be attributed to the activation of prismatic $\langle a\rangle$ slip parallel to LD and the activation of basal $\langle a\rangle$ slip perpendicular to LD.

\section{ACKNOWLEDGMENTS}

Bo Chen acknowledges financial supports by the UK's Engineering and Physical Sciences Research Council, EPSRC Early Career Fellowship Scheme EP/ R043973/1 and East China University of Science and Technology through the Ministry of Education of the People's Republic of China 'the 111 Project'. The authors are grateful for financial supports from the National Natural Science Foundation of China (NSFC 51725503, 51605164) and the ISIS Beam Time Award RB1710270 and ISIS Newton Programme. We extend our sincere thank you to Dr. Dikai Guan from the University of Sheffield (UK) and Dr. Zhuang Liu from Liaoning University of Technology (China) for their help and fruitful discussions about the in-depth interpretation of the EBSD/TKD dataset.

\section{OPEN ACCESS}

This article is licensed under a Creative Commons Attribution 4.0 International License, which permits use, sharing, adaptation, distribution and reproduction in any medium or format, as long as you give appropriate credit to the original author(s) and the source, provide a link to the Creative Commons licence, and indicate if changes were made. The images or other third party material in this article are included in the article's Creative Commons licence, unless indicated otherwise in a credit line to the material. If material is not included in the article's Creative Commons licence and your intended use is not permitted by statutory regulation or exceeds the permitted use, you will need to obtain permission directly from the copyright holder. To view a copy of this licence, visit http://creat ivecommons.org/licenses/by/4.0/.

\section{APPENDIX A: GRAIN GROWTH KINETICS OF POST-DYNAMIC RECRYSTALLIZED CP-TI}

Grain growth is a process of reduction of the internal energy of a material at high temperature by reducing the total volume of grain boundaries. Grain growth occurs by the movement of grain boundaries driven by the local curvature. The kinetics of grain growth can be represented as ${ }^{[47]}$ :

$$
\bar{D}^{1 / n}-\bar{D}_{0}^{1 / n}=t k_{0} \exp \left(-\frac{Q}{R T}\right),
$$

where $\bar{D}$ is the average grain size after annealing at temperature $T$ for a given time $t$, and $\bar{D}_{0}$ is the initial

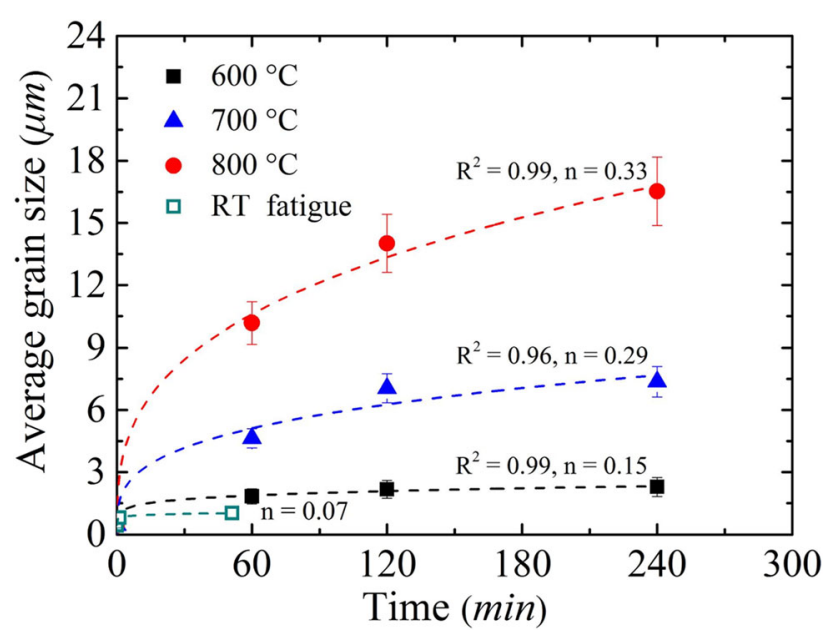

Fig. 11-Grain growth kinetics of MDF cp-Ti as a function of annealing and fatigue time at different temperature. Note: the fatigue time was converted from the cycles. 
grain size (i.e., as-MDF condition). $n$ is the grain/subgrain growth exponent, while $k_{0}$ is the temperature-dependent rate constant. $R$ is the gas constant and $Q$ is the activation energy. Figure 11 presents the averaged grain sizes in both the high-temperature annealed and RT fatigued conditions as well as the derived $n$. The value of $n$ physically corresponds to the grain boundary mobility and is dependent on the interfacial energy and atomic diffusion. It can be seen in Figure 11 that $n$ increased with $T$ from $0.15\left(600{ }^{\circ} \mathrm{C}\right)$ to $0.33\left(800{ }^{\circ} \mathrm{C}\right)$. For single-phase materials under annealing, the $n$ value range were reported from 0.2 to 0.5 ; a higher material purity tended to make $n$ approaching $0.5 \cdot{ }^{[48]}$ By contrast, the fatigued MDF cp-Ti showed a much smaller $n$ value (0.07), indicating that the underlying mechanism was different between high-temperature annealing and RT fatigue loading-induced grain growth.

To calculate the $Q$ value, the average value of $n=$ 0.30 was used. For the present post-dynamic recrystallized cp-Ti, the average $Q$ value was thus determined to be $241.7 \mathrm{~kJ} / \mathrm{mol}$ with a very small standard deviation of $\pm 17.6 \mathrm{~kJ} / \mathrm{mol}$. By comparing with the literature data available for $\mathrm{cp}$-Ti, the present $Q$ value for MDF cp-Ti $(241.7 \mathrm{~kJ} / \mathrm{mol})$ appeared to be higher than that derived from the recrystallization of cold rolled cp-Ti (156.8 $\mathrm{kJ} / \mathrm{mol})^{[49]}$ and that from the 8-pass ECAP $\mathrm{cp}$-Ti $(179.0$ $\mathrm{kJ} / \mathrm{mol})^{[47]}$. For the UFG $\mathrm{cp}$-Ti with initial grain size of $1.4 \mu \mathrm{m}$, the recrystallization activation energy $Q$ was determined to be $248.0 \mathrm{~kJ} / \mathrm{mol},{ }^{[50]}$ while a value of 342.0 $\mathrm{kJ} / \mathrm{mol}$ was reported for a 10 -pass ECAP cp-Ti. ${ }^{[51]}$ In light of the significant $Q$ value inconsistency in the literature, it is not appropriate to draw a conclusion. But, the $Q$ value in the present MDF cp-Ti, as well as the previous ECAP cp-Ti ${ }^{[50,51]}$ except for one outlier, ${ }^{[47]}$ were significantly greater than that of lattice self-diffusion of $\operatorname{Ti}(169.1 \mathrm{~kJ} / \mathrm{mol}) .^{[52]}$ This seems to be backed up with our knowledge of the relatively good thermal stability of SPD metals compared with the conventional plastic deformed ones.

\section{REFERENCES}

1. R.D. Doherty, D.A. Hughes, F.J. Humphreys, J.J. Jonas, D. Juul Jensen, M.E. Kassner, W.E. King, T.R. McNelley, H.J. McQueen, and A.D. Rollett: Mater. Sci. Eng. A, 1997, vol. 238, pp. 219-74.

2. T. Sakai, A. Belyakov, R. Kaibyshev, H. Miura, and J.J. Jonas: Prog. Mater. Sci., 2014, vol. 60, pp. 130-207.

3. K. Huang and R.E. Logé: Mater. Des., 2016, vol. 111, pp. 548-74.

4. R.Z. Valiev: Nat. Mater., 2004, vol. 3, pp. 511-16.

5. R.Z. Valiev, R.K. Islamgaliev, and I.V. Alexandrov: Prog. Mater. Sci., 2000, vol. 45, pp. 103-89.

6. X. Yang, Y. Zhu, H. Miura, and T. Sakai: Trans. Nonferr. Met. Soc. China, 2010, vol. 20, pp. 1269-74.

7. X. Yang, H. Miura, and T. Sakai: Mater. Trans., 2005, vol. 46, pp. 2981-87.

8. D. Yu, D. Zhang, Y. Luo, J. Sun, J. Xu, and F. Pan: Mater. Sci. Eng. A, 2016, vol. 658, pp. 99-108.

9. Z. Yan, D. Wang, X. He, W. Wang, H. Zhang, P. Dong, C. Li, Y. Li, J. Zhou, Z. Liu, and L. Sun: Mater. Sci. Eng. A, 2018, vol. 723 , pp. 212-20.

10. P. Zhao, B. Chen, J. Kelleher, G. Yuan, B. Guan, X. Zhang, and S. Tu: Acta Mater., 2019, vol. 174, pp. 29-42.
11. G.S. Dyakonov, E. Zemtsova, S. Mironov, I.P. Semenova, R.Z. Valiev, and S.L. Semiatin: Mater. Sci. Eng. A, 2015, vol. 648, pp. 305-10.

12. G. Gottstein: Physical Foundations of Materials Science, 1st ed., Springer, Berlin, 2004.

13. H. Jazaeri and F.J. Humphreys: Acta Mater., 2004, vol. 52, pp. 3239-50.

14. N. Bozzolo, N. Dewobroto, T. Grosdidier, and F. Wagner: Mater. Sci. Eng. A, 2005, vol. 397, pp. 346-55.

15. A. Ostapovets, P. Šedá, A. Jäger, and P. Lejček: Scripta Mater., 2011, vol. 64, pp. 470-73.

16. K.Y. Zhu, B. Bacroix, T. Chauveau, D. Chaubet, and O. Castelnau: Metall. Mater. Trans. A, 2009, vol. 40A, pp. 2423-34.

17. M.G. Jiang, C. Xu, H. Yan, G.H. Fan, T. Nakata, C.S. Lao, R.S. Chen, S. Kamado, E.H. Han, and B.H. Lu: Acta Mater., 2018, vol. 157, pp. 53-71.

18. X. Liu and J. Wang: Sci. Rep., 2016, vol. 6, p. 21393:1-8.

19. R. Bonnet, E. Cousineau, and D.H. Warrington: Acta Crystallogr. A, 1981, vol. 37, pp. $184-89$

20. D.G. Brandon: Acta Metall., 1966, vol. 14, pp. 1479-84.

21. J. Favre, D. Fabregue, D. Piot, N. Tang, Y. Koizumi, E. Maire, and A. Chiba: Metall. Mater. Trans. A, 2013, vol. 44A, pp. 5861-75.

22. A. Galiyev, R. Kaibyshev, and G. Gottstein: Acta Mater., 2001, vol. 49, pp. 1199-1207.

23. M. Beck, M. Morse, C. Corolewski, K. Fritchman, C. Stifter, C. Poole, M. Hurley, and M. Frary: Metall. Mater. Trans. A, 2017, vol. 48 A, pp. $3831-42$.

24. F.M. Shore, M. Morakabati, S.M. Abbasi, and A. Momeni: $J$. Mater. Eng. Perform., 2014, vol. 23, pp. 1424-33.

25. M. El Wahabi, L. Gavard, F. Montheillet, J.M. Cabrera, and J.M. Prado: Acta Mater., 2005, vol. 53, pp. 4605-12.

26. M.R. Sandstr and R. Lagneborg: Acta Metall., 1975, vol. 23, pp. $387-98$.

27. S.R. Agnew, M.H. Yoo, and C.N. Tomé: Acta Mater., 2001, vol. 49 , pp. 4277-89.

28. J.J. Jonas, X. Quelennec, L. Jiang, and E. Martin: Acta Mater., 2009, vol. 57, pp. 2748-56.

29. D.S. Gianola, S. Van Petegem, M. Legros, S. Brandstetter, H. Van Swygenhoven, and K.J. Hemker: Acta Mater., 2006, vol. 54, pp. 2253-63.

30. G.J. Fan, L.F. Fu, H. Choo, P.K. Liaw, and N.D. Browning: Acta Mater., 2006, vol. 54, pp. 4781-92.

31. Y.M. Wang, A.V. Hamza, and E. Ma: Acta Mater., 2006, vol. 54, pp. $2715-26$.

32. J.C.M. Li: Phys. Rev. Lett., 2006, vol. 96, p. 215506(1-4)

33. P. Andriot, P. Lalle, and J.P. Dejean: AIP Conf. Proc., 1994, vol. 309, pp. 1009-12.

34. H.W. Hoppel, Z.M. Zhou, H. Mughrabi, and R.Z. Valiev: Philos. Mag. A, 2002, vol. 82, pp. 1781-94.

35. Y. Zhu, X. Liao, and X. Wu: JOM, 2008, vol. 60, pp. 60-64.

36. C.M. Cepeda-Jiménez, J.M. Molina-Aldareguia, and M.T. Pérez-Prado: Acta Mater., 2015, vol. 88, pp. 232-44.

37. A.A. Salem, S.R. Kalidindi, and S.L. Semiatin: Acta Mater., 2005, vol. 53, pp. 3495-3502.

38. L. Wu, A. Jain, D.W. Brown, G.M. Stoica, S.R. Agnew, B. Clausen, D.E. Fielden, and P.K. Liaw: Acta Mater., 2008, vol. 56, pp. 688-95.

39. M.T. Perez-Prado, G. Gonzalez-Doncel, O.A. Ruano, and T.R. McNelley: Acta Mater., 2001, vol. 49, pp. 2259-68.

40. H. Conrad: Prog. Mater. Sci., 1981, vol. 26, pp. 123-403.

41. S. Biswas, B. Beausir, L.S. Toth, and S. Suwas: Acta Mater., 2013, vol. 61 , pp. $5263-77$.

42. Y. Zhang and C.J.L. Wilson: J. Struct. Geol., 1997, vol. 19, pp. 875-85.

43. N. Benmhenni, S. Bouvier, R. Brenner, T. Chauveau, and B. Bacroix: Mater. Sci. Eng. A, 2013, vol. 573, pp. 222-33.

44. T. Mayama, M. Noda, R. Chiba, and M. Kuroda: Int. J. Plast., 2011, vol. 27, pp. 1916-35.

45. N.P. Gurao, R. Kapoor, and S. Suwas: Acta Mater., 2011, vol. 59, pp. $3431-46$

46. X. Huang, K. Suzuki, M. Yuasa, and Y. Chino: J. Mater. Sci., 2014, vol. 49, pp. 3166-76. 
47. M. Hoseini, M.H. Pourian, F. Bridier, H. Vali, J.A. Szpunar, and P. Bocher: Mater. Sci. Eng. A, 2012, vol. 532, pp. 58-63.

48. H. Gleiter: Acta Mater., 2000, vol. 48, pp. 1-29.

49. R.J. Contieri, M. Zanotello, and R. Caram: Mater. Sci. Eng. A, 2010, vol. 527, pp. 3994 4000 .

50. T. Kubina, J. Dlouhy, M. Kover, and J. Hodek: Mater. Sci. Forum, 2014, vol. 782, pp. 415-20.
51. K. Hajizadeh, S.G. Alamdari, and B. Eghbali: Physica B, 2013, vol. 417, pp. 33-38.

52. C.J. Smithells and E.A. Brandes: Smithells Metals Reference Book, 5th ed., Butterworths, London, 1992.

Publisher's Note Springer Nature remains neutral with regard to jurisdictional claims in published maps and institutional affiliations. 